Review article

\title{
Engineered non-invasive functionalized dendrimer/dendron-entrapped/ complexed gold nanoparticles as a novel class of theranostic (radio) pharmaceuticals in cancer therapy
}

\author{
Serge Mignani ${ }^{\mathrm{a}, \mathrm{b},{ }^{* *}}$, Xiangyang $\mathrm{Shi}^{\mathrm{c},{ }^{* * *}}$, Valentin Ceña ${ }^{\mathrm{d}}$, João Rodrigues ${ }^{\mathrm{b}}$, Helena Tomas ${ }^{\mathrm{b}}$, \\ Jean-Pierre Majoral ${ }^{\mathrm{e}, \mathrm{f}, *}$ \\ ${ }^{a}$ Université Paris Descartes, PRES Sorbonne Paris Cité, CNRS UMR 860, Laboratoire de Chimie et de Biochimie Pharmacologiques et Toxicologique, 45, rue des Saints \\ Peres, 75006 Paris, France \\ b CQM - Centro de Química da Madeira, MMRG, Universidade da Madeira, Campus da Penteada, 9020-105 Funchal, Portugal \\ ${ }^{\mathrm{c}}$ College of Chemistry, Chemical Engineering and Biotechnology, Donghua University, Shanghai 201620, PR China \\ d CIBERNED, ISCII, MAdrid; Unidad Asociada Neurodeath, Universidad de Castilla-La Mancha, Avda. Almansa, 14, 02006 Albacete, Spain \\ ${ }^{\mathrm{e}}$ Laboratoire de Chimie de Coordination du CNRS, 205 route de Narbonne, 31077 Toulouse Cedex 4, France \\ ${ }^{\mathrm{f}}$ Université Toulouse 118 route de Narbonne, 31077 Toulouse Cedex 4, France
}

\section{A R T I C L E I N F O}

\section{Keywords:}

Dendrimers

Dendrons

Gold(0)/(III) nanoparticles

Gene and drug delivery

Cancer therapy

Theranostic strategy

\begin{abstract}
A B S T R A C T
Nanomedicine represents a very significant contribution in current cancer treatment; in addition to surgical intervention, radiation and chemotherapeutic agents that unfortunately also kill healthy cells, inducing highly deleterious and often life-threatening side effects in the patient. Of the numerous nanoparticles used against cancer, gold nanoparticles had been developed for therapeutic applications. Inter alia, a large variety of dendrimers, i.e. soft artificial macromolecules, have turned up as non-viral functional nanocarriers for entrapping drugs, imaging agents, and targeting molecules. This review will provide insights into the design, synthesis, functionalization, and development in biomedicine of engineered functionalized hybrid dendrimer-tangled gold nanoparticles in the domain of cancer theranostic. Several aspects are highlighted and discussed such as 1) dendrimer-entrapped gold $(0)$ hybrid nanoparticles for the targeted imaging and treatment of cancer cells, 2) dendrimer encapsulating gold(0) nanoparticles (Au DENPs) for the delivery of genes, 3) Au DENPs for drug delivery applications, 4) dendrimer encapsulating gold radioactive nanoparticles for radiotherapy, and 5) dendrimer/dendron-complexed gold(III) nanoparticles as technologies to take down cancer cells.
\end{abstract}

\section{Introduction}

In medicine, nanomedicine which is an interdisciplinary field of science have sparked an extraordinary growing interest to achieve medical benefit. Also, nanotechnology in nanomedicine can overcome biological obstacles to treat severe diseases like complex cancers, which are presently difficult to cure completely. The most widespread cancers are breast, colorectal, lung, prostate as well stomach and liver cancer. [1] Importantly, over the last decade, remarkable steps forward have been made in advancing cancer diagnosis and treatment with a move toward increased sensitivity, speed, and cost-effectiveness. [2] Nanomedicine has made a very significant contribution to current cancer treatments, in addition to surgical intervention; importantly, radiation and chemotherapeutic agents unfortunately also kill normal cells by inducing highly deleterious and often life-threatening side effects in the patient. [3] Consequently, to overcome these problems, within the nanomedicine domain, the development of highly efficient platforms for cancer therapy based on engineered nanoparticles (NPs) for drug delivery has been investigated as so-called "magic bullets". [4] Indeed, in order to decrease the side effects of highly toxic anti-cancer drugs, the

\footnotetext{
* Correspondence to: J.-P. Majoral, Laboratoire de Chimie de Coordination du CNRS, 205 route de Narbonne, 31077 Toulouse Cedex 4 , France.

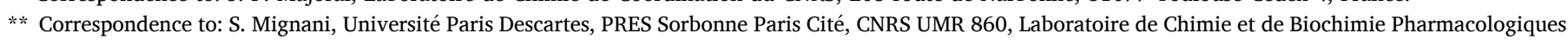
et Toxicologique, 45, rue des Saints Peres, 75006 Paris, France.

$* * *$ Corresponding author.

E-mail addresses: serge.mignani@parisdescartes.fr, serge.mignani@staff.uma.pt (S. Mignani), xshi@dhu.edu.cn (X. Shi), joaoc@staff.uma.pt (J. Rodrigues), lenat@staff.uma.pt (H. Tomas), majoral@lcc-toulouse.fr (J.-P. Majoral).
} 
development of drug delivery systems for cancer chemotherapy have been employed.

Liposomes, micelles, polymeric nanoparticles, nanocrystals, solid lipid nanoparticles, nanocages, metal nanoparticles (e.g. gold, iron), nanocrystals, graphene oxide, carbon nanotubes, and dendrimers have been used extensively as nanocarriers, and several of them have been approved for clinical use. [5] The two NPs in clinic are the first FDA approved (1995) PEGylated liposome injections Doxil ${ }^{\circledR}$ and Caelyx ${ }^{\circledR}$ (doxorubicin (DOX) $\mathrm{HCl}\left(\right.$ Adriamycin $\left.{ }^{\circledR}\right)$ ), and paclitaxel albumin-bound particles called Abraxane ${ }^{\mathrm{TM}}$. [6]

Dendrimers are different in comparison to conventional polymers, and represent a unique class of macromolecules offering well-defined 3D nanoarchitectures. The spherical shape, the surface functionalities and size of which can be precisely controlled affording high degree of molecular uniformity. Size and surface characteristics are the most important features to be managed to develop safe and biocompatible dendrimers. Presently, a large variety of dendrimers have emerged as non-viral versatile nanocarriers. These radially symmetric monodisperse macromolecules are described as highly branched, star-shaped with nanometer size. Three major macromolecular architectural components can characterize dendrimers: a central core, interior dendritic structure including branches, and a peripheral surface with diverse functional groups. The drugs of interest can be entrapped by encapsulation within the cavities of dendrimers, or covalently conjugated with a cleavable linker sensitive to, for instance, acidic pH. [7] Dendrimers have been widely used to deliver anticancer drug by passive and active targeting strategies. Dendrimers represent ideal vectors for drugs for therapeutic purposes or imaging molecules for diagnostic use. Based on the different attributes of dendrimers including pharmacokinetic, pharmacodynamic and toxicological properties, the concept of dendrimer space has been presented and developed. [8] The main advantages of dendrimers are as follows: 1) strong functionalization of surface, 2) hydrophobic and hydrophilic drugs can be encapsulated, conjugated or complexed, 3) facile control of the synthesis as well degradation process, 4) high penetration into the cell membranes, 5) high structural homogenicity, 6) high water solubility with adequate surface functionalization, 7) meaningfully lower viscosity versus linear polymer, 8) higher ligand density on the surface than linear polymers, 9) multiple routes of administration: intravenous (iv), intraperitoneal (ip), ocular, transdermal, oral (po), intranasal, and pulmonary) [9] versus micelles and liposomes for which only the iv route is possible, 10) controlled biodistribution, 11) high drug loading capacity (local concentration effect), 12) enhanced permeability and retention (EPR) effect for the accumulation in tumor tissues, $[10,11]$ whereas the main disadvantages are 1 ) few examples in clinic due to translational issues including good manufacturing practices (GMP) production and quality control. This aspect is general for any nanoparticles in medicine [12], 2) high cost of production, and 3) challenged EPR effect: 'the EPR effect works in rodents but not in humans'. [13] All these advantages have contributed to the development of dendrimers in nanomedicine.

The historical applications of gold in art and ancient medicine dates back to the dawn of time. Naturally, the body does not have gold nanoparticles, but several formulations in biomedicine with gold molecule are generally non-toxic and non-immunogenic, and consequently suitable for in vivo studies [14,15]. Importantly, the tailored chemical (e.g. facile surface chemistry), and physical (e.g. comparable size relative to proteins) properties of gold nanoparticles allow their accumulation, for instance in tumor tissues and cells, and they can be detected and quantified with high sensitivity [16,17]. Importantly, based on the ability of gold nanoparticles to intensively absorb X-ray radiation, they can be used as in cancer radiation therapy, as well as imaging contrast agents in diagnostic CT (computed tomography) scans [18].

Over the past decades, nanotheranostic nanoparticles (TNPs) that simultaneously transmit diagnostic information and monitor the therapy process in situ have been developped mainly in nano-oncology realm.
[19] These TNPs dispose of unique physical and chemical properties to target desired cells and tissues producing therapeutic and imaging action against the disease. [20] Multiple imaging approaches were used such as optical imaging, ultrasound (US), magnetic resonance imaging (MRI), computed tomography (CT), single-photon computed tomography (SPECT) and positron emission tomography (PET). [21] Importantly, NPTs are able to increase the accumulation and delivery of encapsulated or conjugated biologically active compounds in tumors, which enhances therapeutic efficacy and reduces side effects on healthy tissue. [22] An interesting analysis to develop ideal TNPs was advocated by Chen et al. [23] The Table 1 shows few selected TNPS in oncology therapeutic domain, and consequently does not present exhaustive list of TNPS. To extend a panoramic view about the development of TNPS in the oncology field, itltt is important to note, that for example, mesoporous silica nanoparticles (MSN) in the theranostic strategy were developped with several imaging technique including photoacustical (near infrared radiation, NIR) [24], ultrasound [25], magnetic resonance (Table 1), optical (e.g. NIR, visible light) [26], and radionucleotide-based (NIR). [27] In vitro and in vivo advances in theranostic nanocarriers of doxorubicin based on iron oxide and gold nanoparticles were highlighted by Gautier et al. including hybrid and metallic nanocarriers. [28] Recently, hybrid mesoporous silica and hydroxyapatite nanoparticles nanocarriers for theranostic applications were described. [29,30] Table 2 depicts selected therapeutic applications of theranostic principle with dendrimers in oncoly except gold NPs which is the aim of this review. [31]

Several examples of the design of targeted dendrimers and dendrons for theranostic applications in oncology were highlighted, and selected examples were depicted in Table 2. In brief, using dendrimers or dendrons as stabilizers or templates, on one hand, the size of the in-situ formed Au NPs can be readily controlled by dendrimers/dendrons through a reducing reaction; on the other hand, with the combination of dendrimers/dendrons and Au NPs, both properties of dendrimers/dendrons and Au NPs can be rendered. Hence, there are many opportunities that can be explored for theranostic applications in cancer therapy based on the dendrimer/dendron-complexed Au NPs. [51] These are the biggest advantages of dendrimer/dendron-complexed Au NPs. The only disadvantage of the combination could be the high cost of commercially available such as PAMAM dendrimers, limiting their uses in some developing countries.

In spite of the large amount of research carried out over decades, few dendrimers have crossed the milestone of entering the clinic. In the dendrimer field, the pharmaceutical company Starpharma Holdings Ltd. (Melbourne, Australia) succeeded in introducing dendrimers, as first-inclass NPs, in the market under the brand name Vivagel ${ }^{\mathrm{TM}}$ (SPL7013). This dendrimer have 32 sodium 1-(carboxymethoxy)naphthalene-3,6disulfonate groups on its surface. Phase II double-blind trials demonstrated retention and duration of activity against HIV and HSV-2, as well as prevention of bacterial vaginosis. VivaGel ${ }^{\mathrm{TM}}$ demonstrated statistically significant efficacy in pivotal Phase III trials to treat bacterial vaginosis. $[70,71]$ Another interesting dendrimer Givosiran (Givlaari ${ }^{\mathrm{TM}}$ ) for the treatment of adults with acute hepatic porphyria, was developed by Alnylam. Givosiran bears a double-stranded siRNA containing 162 'F-ribonucleosides units and six thiophosphate linkages. [72]

This review will describe the recent developments in the design, synthesis, functionalization, in biomedicine of engineered functionalized dendrimer-entrapped gold(0) and dendrimer-complexed gold(III) nanoparticles in cancer therapy. The therapeutic applications of dendrimer-stabilized AuNPs and AuNP-cored dendrimers are not within the scope of this review. 
Table 1

Selected TNPS in oncology therapeutic domain.

\begin{tabular}{|c|c|c|c|c|c|}
\hline TNPs types & Materials involved & Anticancer agents loaded & Contrast agenst & $\begin{array}{l}\text { Targeting } \\
\text { groups }\end{array}$ & Ref. \\
\hline Carbon nanotubes & Carbon & Cisplatin & Quantum dots & $\mathrm{EGF}^{\mathrm{a}}$ & [32] \\
\hline Drug conjugates & HPMA $^{\mathrm{b}}$ & & DY-615 & $\mathrm{RGD}^{\mathrm{c}}$ & [33] \\
\hline Aliphatic polyesters & $\begin{array}{l}\text { PLGA }^{\mathrm{d}}+\text { poly(allylamine)/ } \\
\text { PEG }\end{array}$ & Docetaxel & SPION $^{\mathrm{e}}$ & SCA antibody & [34] \\
\hline Micelles & PEG-PLA ${ }^{\mathrm{f}}$ & Doxorubicin & SPION $^{\mathrm{e}}$ & $\mathrm{RGD}^{\mathrm{c}}$ & [35] \\
\hline Core-shell nanoparticles & $\mathrm{PAA}^{\mathrm{g}} / \mathrm{SPION}^{\mathrm{e}}$ & Paclitaxel & SPION $^{\mathrm{e}} / \mathrm{Dil}^{\mathrm{h}}$ & Folic acid & [36] \\
\hline \multirow[t]{7}{*}{ Mesoporous silica nanoparticles } & Silica nanoparticles & Aptamer YQ26 & Fluorescent silica nanoparticles & & [37] \\
\hline & Silica nanoparticles & Doxorubicin & $\begin{array}{l}\text { Gd(III) complexed with bovine serum } \\
\text { albumin }\end{array}$ & $\begin{array}{l}\text { Hyaluronic } \\
\text { acid }\end{array}$ & [38] \\
\hline & $\begin{array}{l}\text { Manganese oxide-capped } \\
\text { mesoporous silica } \\
\text { nanoparticles }\end{array}$ & Doxorubicin & Manganese oxide & & [39] \\
\hline & $\begin{array}{l}\text { Ultrasmall manganese oxide } \\
\text { nanoparticles (USMO) }\end{array}$ & Doxorubicin & Manganese oxide & & [40] \\
\hline & HA-CD $/ \mathrm{Gd} /$ tirapazamide & & $\begin{array}{l}\text { Gd(III) and porphyrin photosensitizer } \\
\text { (TPPS4) }\end{array}$ & & [41] \\
\hline & PNIPAM $^{\mathrm{j}} / \mathrm{NHMA} / \mathrm{SPION}^{\mathrm{e}}$ & $\begin{array}{l}\text { Synergic effect: intracellular } \\
\text { hyperthermia and chemotherapy } \\
\text { (doxorubicin) }\end{array}$ & Iron oxide magnetic nanoparticles & & [42] \\
\hline & $\begin{array}{l}\text { PEG-Polylysine/HSV-TK }{ }^{\mathrm{k}} / \\
\text { GCV }^{1} / \text { SPION }\end{array}$ & Gene therapy & Iron oxide magnetic nanoparticles & & [43] \\
\hline $\begin{array}{l}\text { Hydroxyapatite (HAp) functionalized } \\
\text { with europium }(\mathrm{Eu} 3+) \text { and zinc oxide } \\
(\mathrm{ZnO})\end{array}$ & $\mathrm{Ca} / \mathrm{Eu} /\left(\mathrm{PO}_{4}\right)_{6}(\mathrm{OH})_{2} / \mathrm{ZnO}$ & Fluorouracil and curcumin & $\begin{array}{l}\text { Photoluminescence properties of } \\
\text { HAp:Eu }{ }^{3+} \text { and HAp:Eu@ZnO }\end{array}$ & & [44] \\
\hline Cu-based nanoparticles [45] & $\begin{array}{l}\text { PEGylated } \\
\text { Cu2 - xSe nanoparticles, }\end{array}$ & $\begin{array}{l}\text { Imaging, and photothermal therapy } \\
\text { of cancer }\end{array}$ & $\begin{array}{l}\text { Photothermal ablation of tumor and } \\
\text { CT/PA/SPECT imaging of tumor. }\end{array}$ & & [46] \\
\hline Liposomes & Liposomes & $\begin{array}{l}\text { Ruthenium polypyridine complex } \\
\text { (Lipo-Ru) }\end{array}$ & $\begin{array}{l}\text { Ruthenium polypyridine comlex } \\
\text { (Lipo-Ru) }\end{array}$ & & [47] \\
\hline Liposomes & Liposomes & SPION $^{\mathrm{e}}$ & Paclitaxel & & [48] \\
\hline Gold-based nanopaticles & PEG-Gold NPs - Diazine & Gold(0) & Gold $(0)$ & & [49] \\
\hline $\begin{array}{l}\mathrm{P}(\mathrm{MAA}-\text { co-MBA-co-AA })^{\mathrm{m}} \\
\text { nanocontainer }\end{array}$ & P(MAA-co-MBA-co-AA)-Gold & Gold $(0)$ & Doxorubicin & & {$[50]$} \\
\hline \multicolumn{6}{|l|}{ a : Epidermal groth factor. } \\
\hline \multicolumn{6}{|c|}{ b : N-(2-hydroxypropyl)methacrylamide. } \\
\hline \multicolumn{6}{|l|}{ c : Arg-Gly-Asp peptide. } \\
\hline \multicolumn{6}{|l|}{ d : Poly(lactic-co-glycolic acid). } \\
\hline \multicolumn{6}{|c|}{ e : Superparamagnetic iron-oxide nanoparticles. } \\
\hline \multicolumn{6}{|c|}{ f : Polylactic acid. } \\
\hline \multicolumn{6}{|l|}{ : Polyacrylic acid. } \\
\hline \multicolumn{6}{|c|}{ h : 1,1-dioctadecyl-3,3,3,3-tetramethylindocarbocyanine perchlorate. } \\
\hline \multicolumn{6}{|c|}{ i : Per-O-methyl-cyclodextrin-grafted-hyaluronic acid. } \\
\hline \multicolumn{6}{|c|}{ j : Poly(N-isopropylacrylamide). } \\
\hline \multicolumn{6}{|c|}{ k : Herpes simplex virus thymidine kinase. } \\
\hline${ }^{1}:$ Ganciclovir. & & & & & \\
\hline
\end{tabular}

2. Hybrid gold nanoparticles entrapped in dendrimers for gene and drug delivery, and nuclear medicine applications to takle down cancers

\subsection{Dendrimers encapsulating gold(O) nanoparticles (Au DENPS): general principles}

The molecular luminescent AuNPs are chemically inert NPs with a size from 0.3 to $2 \mathrm{~nm}$, and generally showed high X-ray attenuation intensity, higher than the CT contrast media Omnipaque [73].

With the use of non-invasive theranostic functional nanoprobes [74], the major objective of specialized nuclear medicine is to 1) characterize and quantify biological processes involved, for instance, in the diagnosis of early cancer, 2) to stimulate specific drug delivery to tackle cancer, and 3) to track cellular evens. [75] Positron emission tomography (PET) and single-photon emission computed tomography (SPECT) combined with dendrimer platforms have been investigated in nuclear medicine imaging applications to avoid common drawbacks which are associated with radioactive isotopes used in the clinic, including 1) short imaging time, 2) renal toxicity, and 3) non-specificity. [76] Radionuclides which emit positrons and gamma $(\gamma)$ rays strategy can be used in nuclear medicine imaging with high sensitivity, whereas therapeutic radionuclides emitting alpha $(\alpha)$ or beta $(\beta)$ rays represent applicable agents for radiotherapy (RT) applications. Instead of an external radiation source such as X-rays, ionizing radiation emitted from therapeutic radionuclides induces radiation within a short distance, thereby minimalizing side effects in normal tissues. However, although both PET and SPECT imaging technique show strong efficacity, they are limited by their spatial resolution and poor anatomical measurements. Structural imaging modes such as powerful computed tomography (CT) and magnetic resonance (MR) imaging techniques have become matched tools to PET and SPECT imaging technique [77]. Interestingly, the recent development of radioimmunotherapy (RIT) technique which specifically targets cancer cells using monoclonal antibodies (mAbs) has been highlighted [78].

For several decades, multimodal imaging contrast agents incorporated with simultaneously therapeutic radioisotopes for theranostic applications have been under development. [79] Taking advantage of the characteristics of dendrimers as multifunctional nanoplatforms for drug and gene delivery, multimodal imaging, and theranostics [80], two different strategies were developed for the use of radiolabeled dendrimer-based nanodevices: 1) conjugation of radiolabels on the 
Table 2

Selected examples of dendrimers and dendrons for theranostic applications in oncology.

\begin{tabular}{|c|c|c|c|c|}
\hline Dendrimer/dendron types & Contrast agent & Anticancer agent & Targeting moieties & Ref. \\
\hline G5 PAMAM & Fluorecein isothiocyanate & & FGFR $^{\mathrm{a}}$ & [52] \\
\hline G5 PAMAM & Photochemical mechanism & Doxorubicin & Folic acid & [53] \\
\hline PEG-G3.5 PAMAM & CdSe/ZnS quantum dots & & Folic acid & [54] \\
\hline PEG-lipoic acid amphiphilic dendron & Cy5.5 (NIR probe) & Pt(II) derivatives & & [55] \\
\hline G4.5 PAMAM & Magnetic resonance imaging: Gd(III) and Mn(II) & & & [56] \\
\hline G2 and G6 PAMAM & Magnetic resonance imaging: Gd(III) & & & [57] \\
\hline G4 PAMAM & Magnetic resonance imaging: Gd(III) & & Folic acid & [58] \\
\hline G6 PAMAM & Magnetic resonance imaging: Gd(III) & & & [59] \\
\hline Janus dendrimersome: $3,5-\mathrm{C}_{12}-\mathrm{EG}-(\mathrm{OH})_{4}$ & Magnetic resonance imaging: Gd(III) & Prednisolone phosphate & & [60] \\
\hline G3 and G6-PAMAM & Magnetic resonance imaging: ${ }^{19} \mathrm{~F}$ & & & [61] \\
\hline G4 PAMAM & $\begin{array}{l}\text { Magnetic resonance imaging: Iron oxide } \\
\text { nanoparticles }\end{array}$ & $\begin{array}{l}\text { 3,4-difluorobenzylidene- } \\
\text { curcumin }\end{array}$ & Folic acid & [62] \\
\hline G4.5 PAMAM & $\begin{array}{l}\text { Magnetic resonance imaging: Gd-doped ferrite (Gd: } \\
\mathrm{Fe}_{3} \mathrm{O}_{4} \text { nanoparticles }\end{array}$ & Doxorubicin & & [63] \\
\hline $\begin{array}{l}\text { Heterobifunctional polyethylene oxide } \\
\text { (PEO) dendron }\end{array}$ & Gamma scintigraphy: ${ }^{76} \mathrm{Br}$ & & cRGD $^{\mathrm{b}}$ & [64] \\
\hline $\begin{array}{l}\text { Polysulfonamine-based dendrimers } \\
\text { (HPSA) }\end{array}$ & Gamma scintigraphy: ${ }^{188} \mathrm{Re}$ & & $\begin{array}{l}\text { Human-mouse chimeric monoclonal } \\
\text { antibody } \mathrm{CH} 12\end{array}$ & [65] \\
\hline G5 PAMAM & Gamma scintigraphy: ${ }^{131} \mathrm{I}$ & & Folic acid-HPAO & [66] \\
\hline G5 PAMAM & Gamma scintigraphy: ${ }^{131} \mathrm{I}$ & & Chlorotoxin (CTX)- HPAO ${ }^{c}$ & [67] \\
\hline G5 PAMAM & Optical imaging: CY5 dy & & VEGF $^{\mathrm{d}}$ & [68] \\
\hline G5 PAMAM & Near infrared fluorescence: IGG derivative $\mathrm{e}^{\mathrm{e}}$ & Docetaxel & $\mathrm{iRGD}^{\mathrm{f}}$ & [69] \\
\hline
\end{tabular}

a : Recombinant fibroblast growth facor-1.

b : Cyclic arginine-glycine-aspartate motif.

c : 3-(4'-hydroxyphenyl)propionic acid-OSu.

d : Vascular endothelial growth factor.

e : Indocyanine Green derivative cypate.

f : Tumor penetration peptide (CRGDKGPDC).

surface of dendrimers and 2) encapsulation of radiolabels inside the free space (interior space) of dendrimers. For instance, the conjugated labels technetium-99 m (99mTc) and Copper-64 radiopharmaceuticals were developed for SPECT and PET imaging with polyamidoamine (PAMAM) dendrimers [81]. Recently, the analysis of the different interactions between gold and phosphorus dendrimers have been presented as versatile ways to prepare hybrid organic-metallic macromolecules [82].

The most common strategy to prepare hybrid dendrimer-Au(0)NPs is to first mix higher generation dendrimers with tetrachloroauric acid trihydrate $\left(\left[\mathrm{Au}(\mathrm{III}) \mathrm{Cl}_{4}\right]^{-}\right)$gold salt. Complexation between $\left[\mathrm{Au}(\mathrm{III}) \mathrm{Cl}_{4}\right]^{-}$ and dendrimers as both templates and nanoreactor hosts is generally based on electrostatic interactions. Then, reduction of the gold salt using ascorbic acid, sodium citrate or sodium borohydride affords metallic gold (Scheme 1) with generally size distribution ranging between 1 and $2 \mathrm{~nm}$ with good chemical stability [83].

Recently, the easy preparation of chemically stable, and soluble in water, G0-G2 triazine dendrons bearing gold NPs has been advocated by Enciso and colleagues [84]. Reduction of diazonium tetrachloroaurate salts by sodium borohydride afforded corresponding triazine dendrons which are covered with gold nanoparticles (Scheme 2).

In order to prepare non-toxic and non-immunogenic hybrids based on dendrimer-gold nanoparticles for therapeutic applications such as cancer imaging and photothermal therapy, the amino groups located on the surface of PAMAM dendrimers have been modified by the introduction of PEG chains. Consequently, the increase of the circulation time in the blood of these modified dendrimers was observed. Also, to reduce toxicity, a neutral surface of dendrimers can also obtained by the introduction of glycidol groups and the reaction of acetic anhydride [85].

Notably, a very interesting and promising direction is to develop stable and biocompatible non-invasive functionalized dendrimer which entraps gold nanoparticles (AuNPs). Two types of nanoparticles have been developed as templates: 1) dendrimer encapsulating AuNPs (Au DENPs) and 2) dendrimer stabilizing AuNPs (Au DSNPs) [86]. For Au DENPs, one AuNP is encapsulated within each dendrimer as the template macromolecule, and the size of the core of Au NPs are generally

Reducing agent

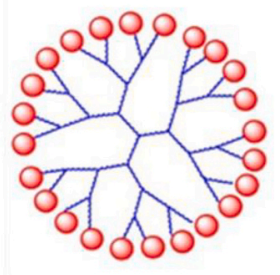

Higher generation of dendrimers (Nanoreactor)

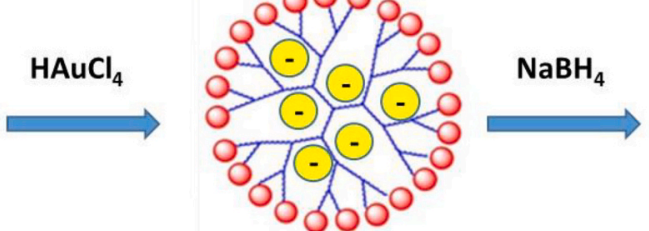

$\left[\mathrm{Au}(\mathrm{III}) \mathrm{Cl}_{4}\right]^{-}$-dendrimers

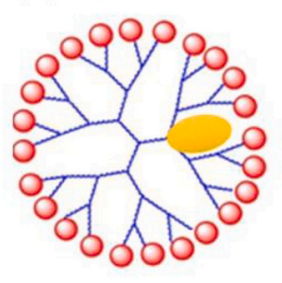

$\mathrm{Au}(0)$-dendrimer NPs

$\mathrm{Au}(0)$ NPs are encapsulated within the void space of dendrimers

Scheme 1. Schematic preparation of dendrimer-entrapped gold nanoparticles. 

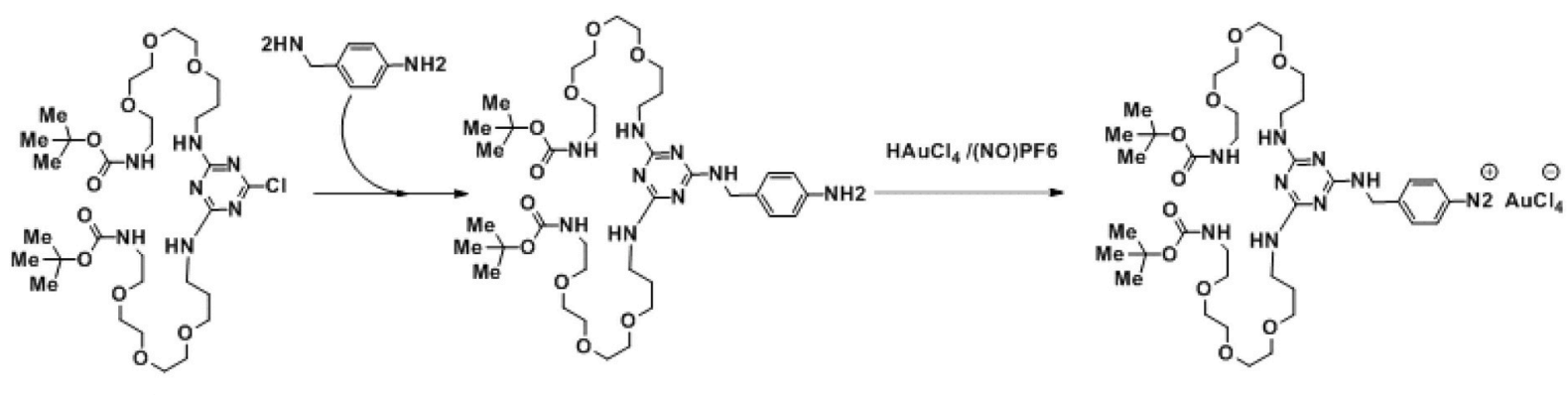

G0

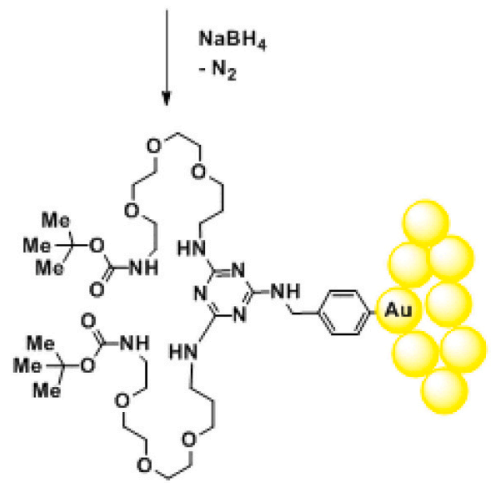

Scheme 2. Synthetic route for the synthesis of G0 triazine dendron-like-coated gold nanoparticles.

smaller than $5 \mathrm{~nm}$, whereas for Au DSNPs, the Au core size is usually larger than $5 \mathrm{~nm}$. In this case, dendrimers play the role of stabilizer. Both of these Au NPs have been used as contrast agents for CT imaging applications. Scheme 3 presents the preparation of one example of DENPs entrapping $\mathrm{Au}(0)$ from G5 PAMAM dendrimer and bearing folic acid (FA) binding with its corresponding receptors on the cancer cell membrane and the preparation of Au DSNPs. [87,88] Importantly, hydrophilic PEGylation of high-generation dendrimers (e.g., G5) increases the size of the dendrimer, allowing it to entrap more elemental Au within the dendrimer interior.

Arguably, based on molecular dynamics (MD) simulation technique, a very interesting study was described by Gonzalez-Nilo et al. about the effect of conditions of synthesis, concentration of gold, and the nature of the functional groups on G4 PAMAM dendrimers on the morphological aspect and slow sedimentation rate of these gold NPs. [89] Absorption related to atomic interactions between PAMAM dendrimers and gold

\section{$\sim$ HOOC-PEG-FA \\ $\sim$ IPEG-COOH}

Au NPs

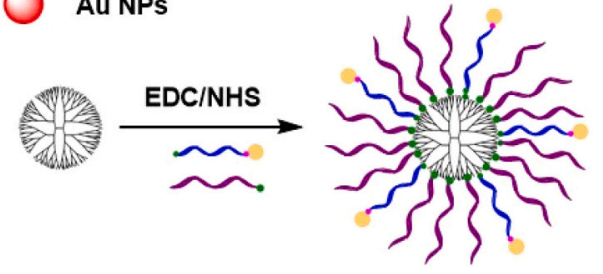

G5. $\mathrm{NH}_{2}$
Synthetic pathway of Au DENPs

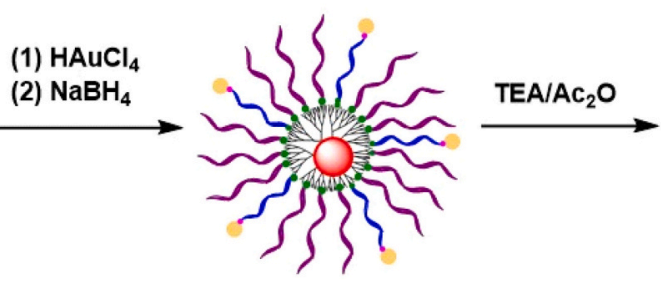

$\left[\left(\mathrm{Au}^{0}\right)_{n}\right.$-G5.NHAC-(PEG-FA)-mPEG] DENPS

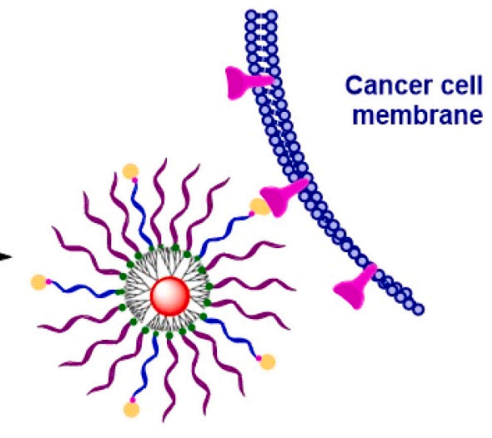

$\left[\left(\mathrm{Au}^{0}\right)_{\mathrm{n}}-\mathrm{G} 5 . \mathrm{NH}_{2}-(\mathrm{PEG}-\mathrm{FA})-m\right.$ PEG $]$ DENPS

\section{Synthetic pathway of Au DSNPs}

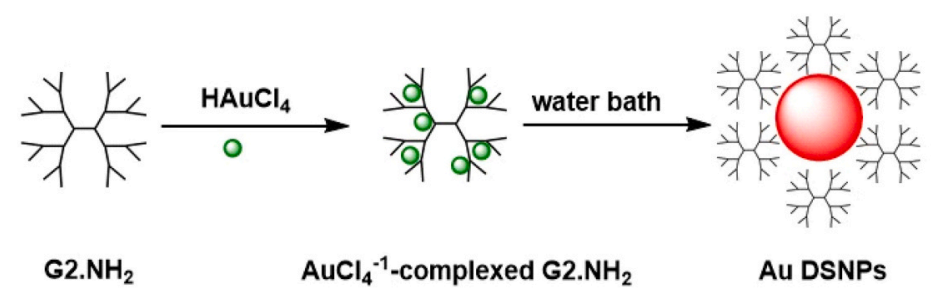

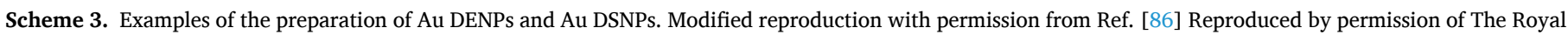
Society of Chemistry. 
nanoparticles depends on the variety of functional groups on the surface of the PAMAM dendrimers. Interestingly, a G4 PAMAM dendrimer with hydroxyl-terminated groups induced aggregates, unlike aminoterminated groups that produced solutions that remained stable after months of storage. Also, the best experimental reaction conditions for the synthesis of AuNPs were ultrasound sonication versus simple agitation and sonication for inducing smaller NPs. MD simulation studies demonstrated that G4 PAMAM-OH has a stronger affinity for the surface of Au compared with cationic G4 PAMAM- $\mathrm{NH}_{3}^{+}$, but all dendrimers have a strong attraction for the Au surface. Interestingly, the adsorption of gold to PAMAM- $\mathrm{NH}_{3}^{+}$is guided by a high enthalpy change, leading to better stabilization of AuNPs. It is interesting to note the encapsulation of $\mathrm{Au} \mathrm{NPs}$ by tetrahedron DNA dendrimer. Gold nanoparticles are encapsulated within the tetrahedron DNA monomers. [90]

\subsection{Hybrid Au DENPs for imaging and treatment of cancer cells}

2.2.1. Combined gamma scintigraphy (SPECT) and computed tomography (CT) approaches

Regarding the development of entrapped radiopaque metal NPs, Shi and colleagues described the design and development of biocompatible G2 PAMAM dendrimers conjugated with PEGylated (polyethylene glycol)-arginine-glycine-aspartic peptide (RGD) as a targeting ligand, and NOTA as the chelator agent of labeled ${ }^{99 \mathrm{~m}} \mathrm{Tc}$, with entrapped gold nanoparticles (Au DENPs); the nanoparticle was named DENPs (Scheme 4) $[91]$.

This original nanoprobe was used for SPECT/CT imaging of $\alpha_{\mathrm{v}} \beta_{3}$ integrin-expressing cancer cells and glioma C6 tumor model. Fig. 4 also shows the quantitative tumor SPECT and CT signal intensity after intravenous injection in tail-vein of the probe. Interestingly, significant change were depicted in the tumor SPECT and CT signal intensities: the SPECT signal intensity was about 24 times higher with NPs with RGD versus without RGD at 30 min post-injection.

(a)
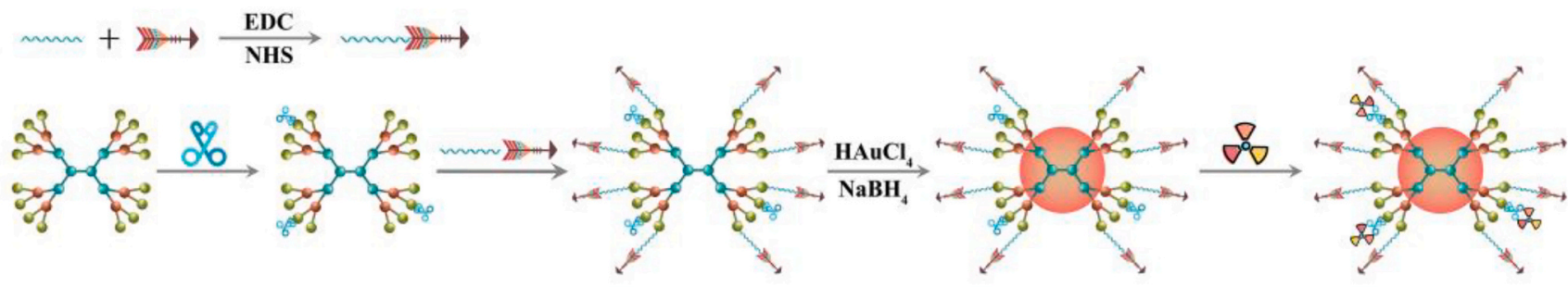

G2 PAMAM dendrimer

COOH-PEG-MAL $\longrightarrow$ RGD

Au NPs $\&^{99 m}$ Te

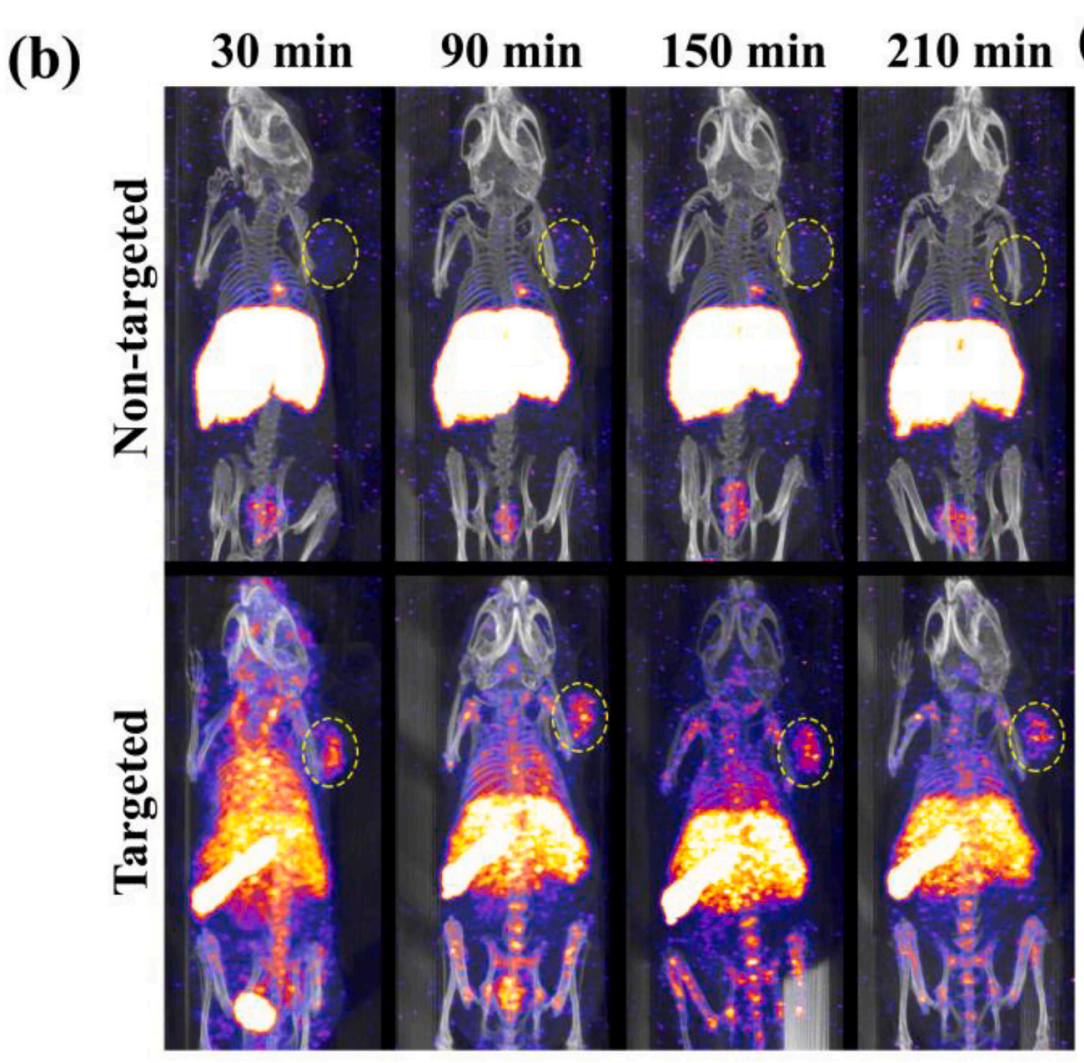

(c)

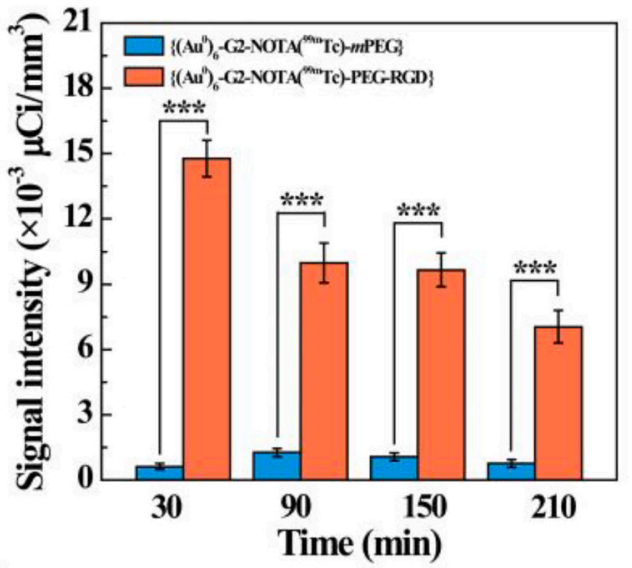

(d)

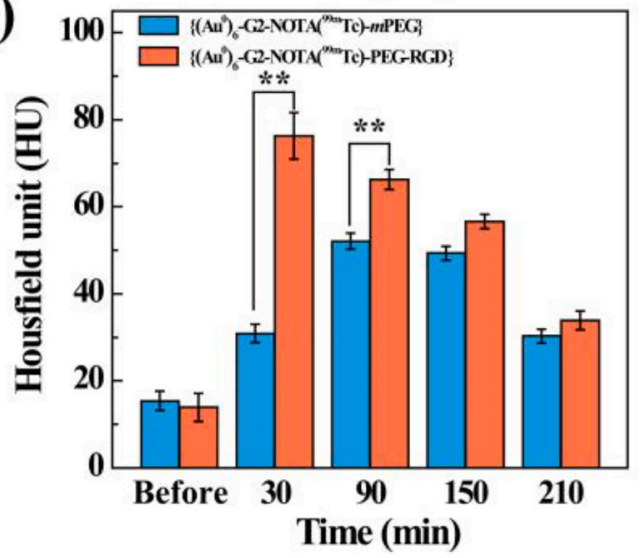

Scheme 4. (a) Schematic preparation of $\left\{(\mathrm{Au0})_{6}\right.$-G2-NOTA $\left({ }^{99 \mathrm{~m}} \mathrm{Tc}\right)$-PEG-RGD $\}$ DENPs and (b-d) in vivo SPECT/CT imaging of tumors using $\left\{(\mathrm{Au} 0)_{6}\right.$-G2-NOTA $\left({ }^{99 \mathrm{~m}} \mathrm{Tc}\right)$-PEG-RGD $\}$ DENPs and non-targeted $\left\{(\mathrm{Au0})_{6}-\mathrm{G} 2-\mathrm{NOTA}\left({ }^{99 \mathrm{~m}} \mathrm{Tc}\right)-\mathrm{mPEG}\right\}$ DENPs. Modified reproduction with permission from Ref. [91]. Reproduced by permission of The Royal Society of Chemistry. 
Notably, the same team designed and developed a CT imaging agent based on the integration of both Au NPs and the SPECT imaging radioisotope ${ }^{99 \mathrm{~m}} \mathrm{Tc}$ within the PEGylated G5 PAMAM dendrimeric nanoplatform for SPECT/CT imaging applications. [92] As shown in Scheme 5, two types of nanoparticles were prepared from G5 PAMAM dendrimer I, i.e. ${ }^{99 \mathrm{~m}} \mathrm{Tc}$-Au-Ac DENPs bearing on its surface $N$-acetylated groups using $\mathrm{Ac}_{2} \mathrm{O}$ for biocompatibility purpose and ${ }^{99 \mathrm{~m}} \mathrm{Tc}-\mathrm{Au}-\mathrm{Gly}$ DENPs with $N$-hydroxylated groups, for biocompatibility purpose, using glycidol on the remaining terminal amino groups of the G5 PAMAM dendrimer III. The chelating moiety of ${ }^{99 \mathrm{~m}}$ Tc was DTPA. The number of DTPA ligands and hydrophilic mPEG moieties (polyethylene glycol monomethyl ether allowing good stability and desirable biocompatibility of the nanoparticles) attached to each G5 dendrimer was statistically 7.6 and 17.6, respectively. These two nanoparticles were colloidally stable, radiostable, and showed excellent hemocompatibility. Fig. 6 shows the synthetic pathways for the preparation of ${ }^{99 m} \mathrm{Tc}-\mathrm{Au}-\mathrm{Ac}$ DENPs and ${ }^{99 m}$ Tc-Au-Gly DENPs and their corresponding SPECT/CT images of the mouse lung, liver, and bladder at $0.5 \mathrm{~h} \mathrm{(a),} 1 \mathrm{~h} \mathrm{(b),} \mathrm{and} 2 \mathrm{~h}$ (c) post-intravenous injection of ${ }^{99 \mathrm{~m}} \mathrm{Tc}-\mathrm{Au}-\mathrm{Ac}$ DENPs and ${ }^{99 \mathrm{~m}} \mathrm{Tc}-\mathrm{Au}-\mathrm{Gly}$ DENPs.

The Au core NPs for both ${ }^{99 m}$ Tc-Au-Ac DENPs and ${ }^{99 m}$ Tc-Au-Gly DENPs have similar size and crystalline lattice, but they displayed different surface plasma resonance (SPR) band locations (Au-Ac DENPs at $530 \mathrm{~nm}$ and Au-Gly DENPs at $510 \mathrm{~nm}$, respectively) due to their varying aggregation behaviors in water with a hydrodynamic size of 96 $\mathrm{nm}$ for the former and $50 \mathrm{~nm}$ for the latter, respectively. These studies show that the surface modification (acetylation versus hydroxylation) availed them of varying biodistribution tendencies, this allowing for preferential imaging of lung using the ${ }^{99 \mathrm{~m}}$ Tc-Au-Ac DENPs and blood vessels using the ${ }^{99 \mathrm{~m}} \mathrm{Tc}-\mathrm{Au}-\mathrm{Gly}$ DENPs. Interestingly, these two nanoplatforms were also used for SPECT/CT imaging of the lymph node of rabbits. Taken together, these studies demonstrate that SPECT/CT imaging of preferential organs can be realized through the chemical modifications of dendrimer surface, in this case hydrophobic acetyl groups over hydrophilic hydroxyl groups.

Further work by the same team reported on the development of G5 PEG-PAMAM dendrimer-entrapped gold nanoparticles showing good CT imaging in New Zealand rabbits [93].

Notably, Li et al. deeicted the development of multifunctional G2 PEG-PAMAM dendrimer entrapping gold NPs (Au DENPs), and bearing ${ }^{99} \mathrm{~m}$ Tc for SPECT/CT imaging of tumors. [94] Thus, Au-DENPs were functionalized by the introduction of 1) folic acid (FA) as targeting ligand through the PEG chain, and 2) cyclic diethylenetriamine penta acetic anhydride (cDTPAA) as the chelator of ${ }^{99 \mathrm{~m}} \mathrm{Tc}$. The obtained $\left\{\left(\mathrm{Au}^{0}\right)_{6}\right.$-G2-DTPA $\left({ }^{99 \mathrm{~m}} \mathrm{Tc}\right)$-PEG-FA $\}$ DENPs, were used for SPECT/CT dual-mode imaging studies of HeLa cancer cells overexpressing FA receptors. Both FA-targeted and non-targeted NPs were cleared by the liver and spleen reticuloendothelial system (RES), and metabolized through the kidney. In the tumor, the concentration of the targeted AuNPs was two times higher than non-targeted Au-NPs due to the FAmediated targeting process.

Interestingly, the same team designed and developed original ${ }^{99 \mathrm{~m}} \mathrm{Tc}$ labeled Au DENP-based G5 dendrimers for early SPECT/CT detection of chemotherapy-induced tumor apoptosis, which is an important aspect for the evaluation of the therapeutic efficiency. [95] As depicted in Scheme 6, G5 PAMAM dendrimers (I) were conjugated with 1) PEGylated duramycin to detect tumor apoptosis. Duramycin recognized the plasma membrane phospholipid phosphatidylethanolamine (PE) during

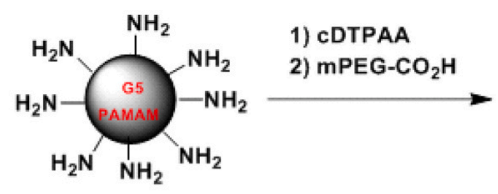

I

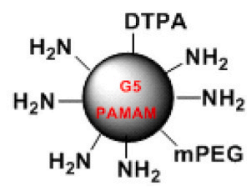

II
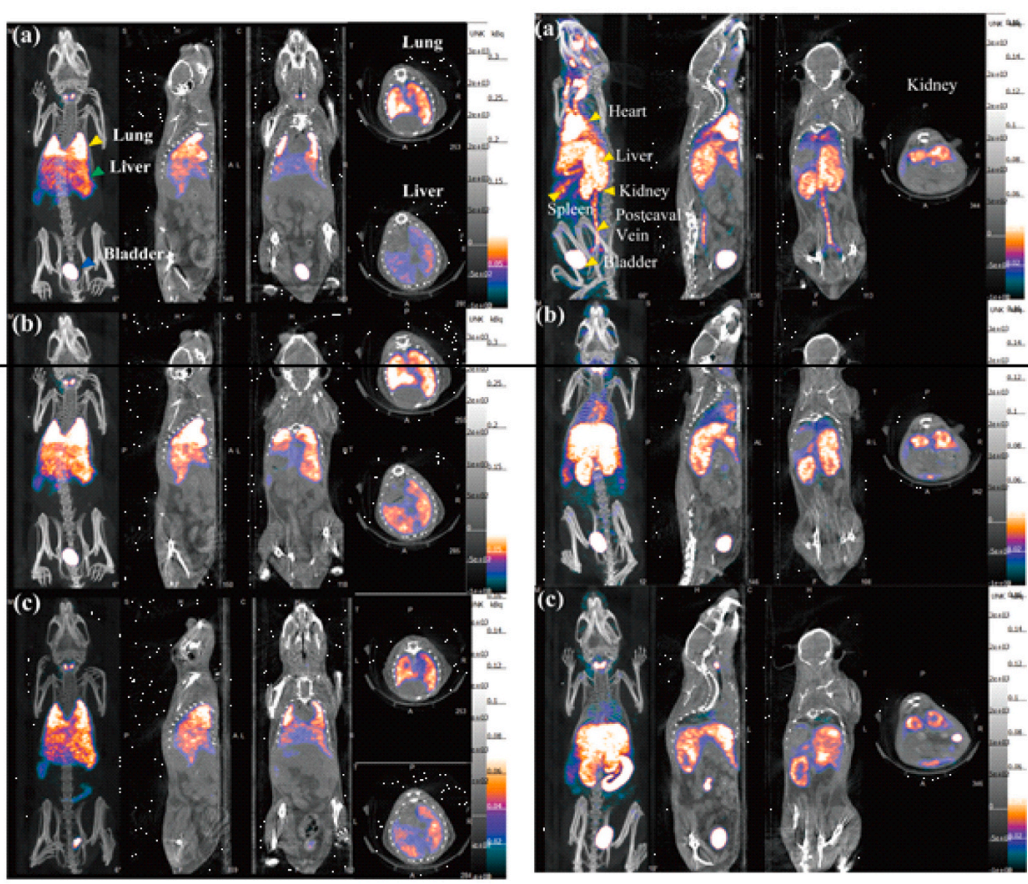

(1)

SPECT/CT images of a mouse lung, liver, and bladder at $0.5 \mathrm{~h} \mathrm{(a),} 1 \mathrm{~h}(\mathrm{~b})$, and $2 \mathrm{~h}(\mathrm{c})$ post intravenous injection of the ${ }^{99 \mathrm{~m}} \mathrm{Tc}-\mathrm{Au}-\mathrm{Ac}$ DENPs (left) and ${ }^{99 \mathrm{~m}} \mathrm{Tc}-\mathrm{Au}-\mathrm{Gly}$ DENPs (right)

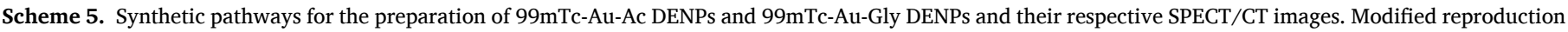
with permission from Ref. [92] Reproduced by permission of The Royal Society of Chemistry. 


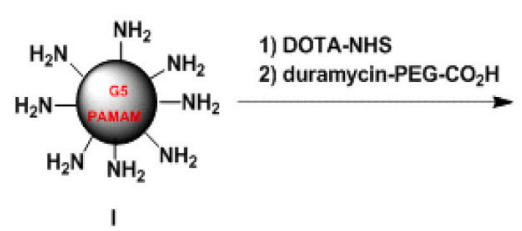

I
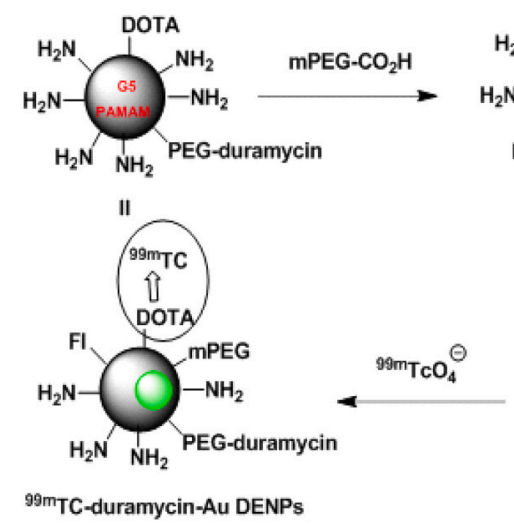

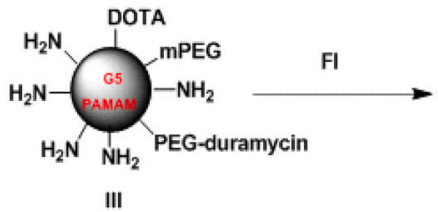

III

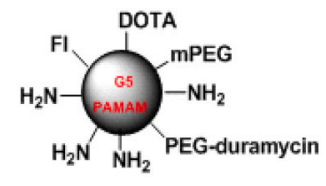

IV

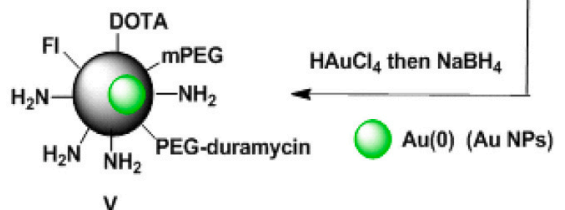

Scheme 6. Synthetic pathways for the preparation of $\left\{\left(\mathrm{Au}^{0}\right)_{200}\right.$-G5.NHAc-DOTA-FI-mPEG-(PEG-duramycin) $\}$ DENPs $\left({ }^{99 m}\right.$ Tc-duramycin-Au DENPs).

physiological processes such as apoptotic cell death, cytokinesis, and coagulation; 2) the radionuclide ${ }^{99 \mathrm{~m}} \mathrm{Tc}$; and 3) fluorescein isothiocyanate (FI); these were entrapped with gold nanoparticles (Au DENPs). The nanoprobe $\left\{\left(\mathrm{Au}^{0}\right)_{200}\right.$-G5.NHAc-DOTA-FI-mPEG-(PEG-duramycin) $\}$ DENPs, called ${ }^{99 \mathrm{~m}} \mathrm{Tc}$-duramycin-Au DENPs, displayed good colloidal stability and cytocompatibility.

Spherical shape with a uniform size distribution (diameters: 2.2-5.9 $\mathrm{nm}$, and hydrodynamic sizes: $287.9-327.0 \mathrm{~nm}$ ) of the Au core of these NPs were observed using TEM image analysis.

Flow cytometry and confocal microscopy studies with $\left\{\left(\mathrm{Au}^{0}\right)_{200}-\mathrm{G} 5\right.$. NHAc-DOTA-FI-mPEG-(PEG-duramycin) $\}$ DENPs against C6 cancer cells showed reinforced fluorescence signals versus the control Au DENPs. In addition, SPECT/CT imaging of C6 cells using in vitro and subcutaneous in vivo xenografted tumor model in mice showed few accumulation of the ${ }^{99 \mathrm{~m}}$ Tc-duramycin-Au DENPs or ${ }^{99 \mathrm{~m}} \mathrm{Tc}$-Au DENPs in the tumors before DOX treatment, but, interestingly, these NPs were well internalized in tumors in vivo after DOX treatment. Among diverse strategies developed in the oncology field, immunotherapeutic treatments that help immune cells to take down cancers, represent a hopeful strategy. Within this strategy, adoptive cell transfer therapy (ACT) using T lymphocytes from patients has recently gained increasing attention. [96,97]

\subsubsection{Computed tomography (CT) approach}

Interesting work performed by Shi et al. concerns the use of G5 PAMAM dendrimer entrapping gold nanoparticles (Au DENPs) functionalized with fluorescein isothiocyanate (FI), PEGylated alphatocopheryl succinate (TOS) and RGD peptide through a PEG chain for chemotherapy targeting and computed tomography (CT) imaging purposes of tumor cells. The remaining amino-terminal groups were acetylated to give Au-TOS-RGD DENPs [98]. $\alpha$-TOS is the most effective form of vitamin $\mathrm{E}$ and results in the inhibition of proliferation and apoptosis of cancer cells (Scheme 7) [99]. Several complementary assays have been performed to evaluate the therapeutic efficiency of this nanoprobe, such as cell viability assays and cell morphological observations as well the evaluation of intracellular reactive oxygen species (ROS) activity and apoptosis pathway. The RGD-rendered targeting specificity of these NPs was confirmed using flow cytometry and confocal microscopy to check their cellular uptake, and using cytotoxicity assay to examine the enhanced therapy efficiency. Likewise, the developed Au-TOS-RGD DENPs showed greater X-ray absorption properties than Omnipaque that is currently used in clinic and shows considerable drawbacks including fast metabolism, toxicity to kidney, and non-specificity to tumors [100].

Another noticeable example of the in vitro and in vivo use of the RGD peptide is for targeted CT imaging of MDA-MB-435 breast carcinoma overexpressing integrin receptors, and using G5 PAMAM dendrimers as nanoreactors (named $\left.\left\{\left(\mathrm{Au}^{0}\right)_{300}-\mathrm{G} 5 \text {.NHAc-(PEG-RGD }\right)_{7}-\mathrm{mPEG}_{8}\right\}$ ), as described by Li. [101] In vivo CT imaging studies have also been performed in mice with MDA-MB-435 xenograft tumors after intravenous injection of $\left\{\left(\mathrm{Au}^{0}\right)_{300} \text {-G5.NHAc-(PEG-RGD) }\right)_{7}$-mPEG8 $\}$ ).

Arguably, the use of low-generation PAMAM dendrimers (e.g., G2) to create partially PEGylated Au DENPs, named $\left\{\left(\mathrm{Au}^{0}\right)_{8}\right.$-G2-mPEG $\}$ DENPs, have been described by Liu et al. for CT imaging applications [102]. The Au DENPs displayed a core size of $2.8 \mathrm{~nm}$ as revealed by TEM and a hydrodynamic size of $276 \mathrm{~nm}$ as examined by dynamic light scattering. The $\left\{\left(\mathrm{Au}^{0}\right)_{8}\right.$-G2-mPEG $\}$ DENPs displayed good cytocompatibility, greater X-ray absorption coefficient than Omnipaque, and ability to CT image the mouse heart (major uptake observed), liver, spleen, lung, kidney, and bladder and the xenografted mouse KB tumor resulting from their extended blood circulation time and the well-known enhanced permeability and retention (EPR) effect [11]. Thus, on the basis of these interesting results, the same team starting from PEGylated G2 PAMAM dendrimers to develop an FA- or chemokine receptor 4 (CXCR4)-targeted ${ }^{99 \mathrm{~m}}$ Tc-labeled Au DENP-based multifunctional nanoprobe for dual

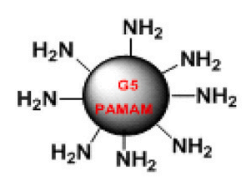

1

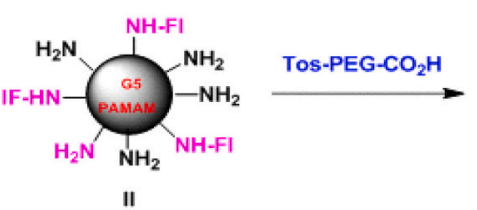

II

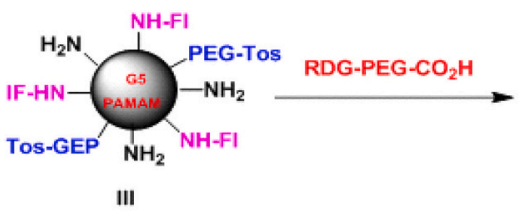

III

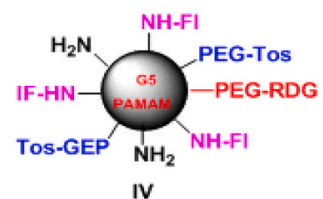

IV

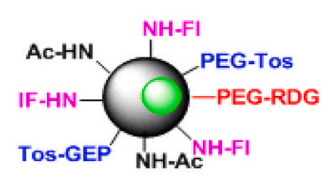

Au-TOS-RGD DENPs

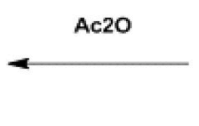

Scheme 7. Synthetic pathway for the preparation of Au-TOS-RGD DENPs. 
modal SPECT/CT imaging of tumors [94,103].

Recently, in the immunotherapeutic domain, multifunctional Au DENPs have been developed to label and track T cells using dual-mode CT/fluorescence imaging [104]. PEGylated G5 PAMAM dendrimers were conjugated with Fluo-4 and entrapped with Au NPs (Scheme 8). The remaining dendrimer surface amino groups were acetylated for biocompatibility purposes, affording the desired final $\left\{\left(\mathrm{Au}^{0}\right)_{25}-\mathrm{G} 5\right.$. NHAc-(PEG) ${ }_{14}$-(Fluo-4) $)_{2}$. After up taken by T cells, Fluo- 4 was released through the cleavage of the ester bond between Fluo-4 and the PEG hydroxyl group by intracellular esterases, inducing its binding with calcium ions and finally generating fluorescence emission.

The $\left.\left\{\left(\mathrm{Au}^{0}\right)_{25} \text {-G5.NHAc-(PEG) }{ }_{14} \text {-(Fluo-4) }\right)_{2}\right\}$ nanoprobe exhibited excellent cytocompatibility to $\mathrm{T}$ cells as confirmed by CCK-8 cell viability assay at a dendrimer concentration up to $5 \mu \mathrm{M}$. In vivo monitoring of $\mathrm{T}$ cells could be realized after subcutaneous injection of the probe using dual-mode CT/fluorescence imaging (Scheme 8). These interesting results confirm the use of multifunctional dendrimer-based nanoprobe for in vivo tracing and monitoring of $\mathrm{T}$ cells for potential clinical applications of T cell-based immunotherapy.

In another work, Shi et al. synthesized lactobionic acid (LA)-decorated G5 PAMAM dendrimers that were entrapped with Au NPs (LA-Au DENPs) for specific human hepatocellular carcinoma CT imaging (Scheme 9, [105]). In vitro flow cytometry studies showed that the LAAu DENPs could specifically target to HepG2 cells in a receptormediated manner. After intravenous or intraperitoneal injection, the LA-Au DENPs enabled CT imaging of a subcutaneous HepG2 mouse tumor model with a high specificity.

Another example is the use of FA-PEGylated G5 PAMAM dendrimer Au NPs (AuNPs) as multifunctional fluorescent nanoprobes for in vitro and in vivo targeted imaging of HeLa cervical cancer cells by CT. [106] The AuNPs were functionalized with fluorescein isothiocyanate (FI), FA, and diatrizoic acid (DTA) and the amino groups on the surface were acetylated for biocompatibility purpose to afford Au DENPs-FI-FA-DTA nanoparticles. DTA is a stabilizer for enhanced computed tomography

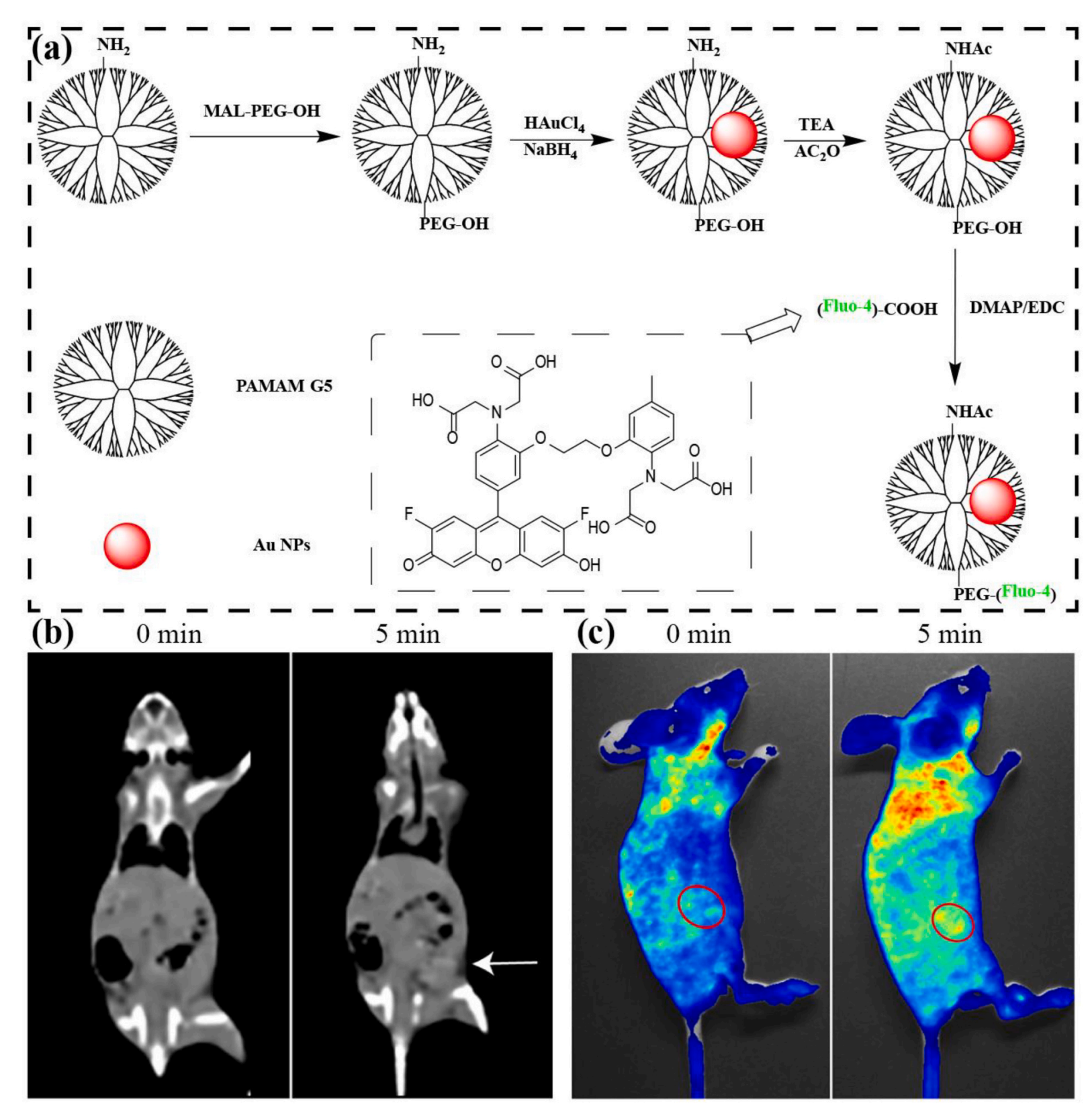

Scheme 8. Synthetic pathways for the preparation of $\left\{\left(\mathrm{Au}^{0}\right)_{25} \text {-G5.NHAc-(PEG) }\right)_{14}$-(Fluo-4 $\left.)_{2}\right\}$ nanoprobe (a), and dual-mode CT/fluorescence images of T cells in vivo (b,c) Modified reproduction with permission from Ref. [104] Copyright 2020 ACS publications. 

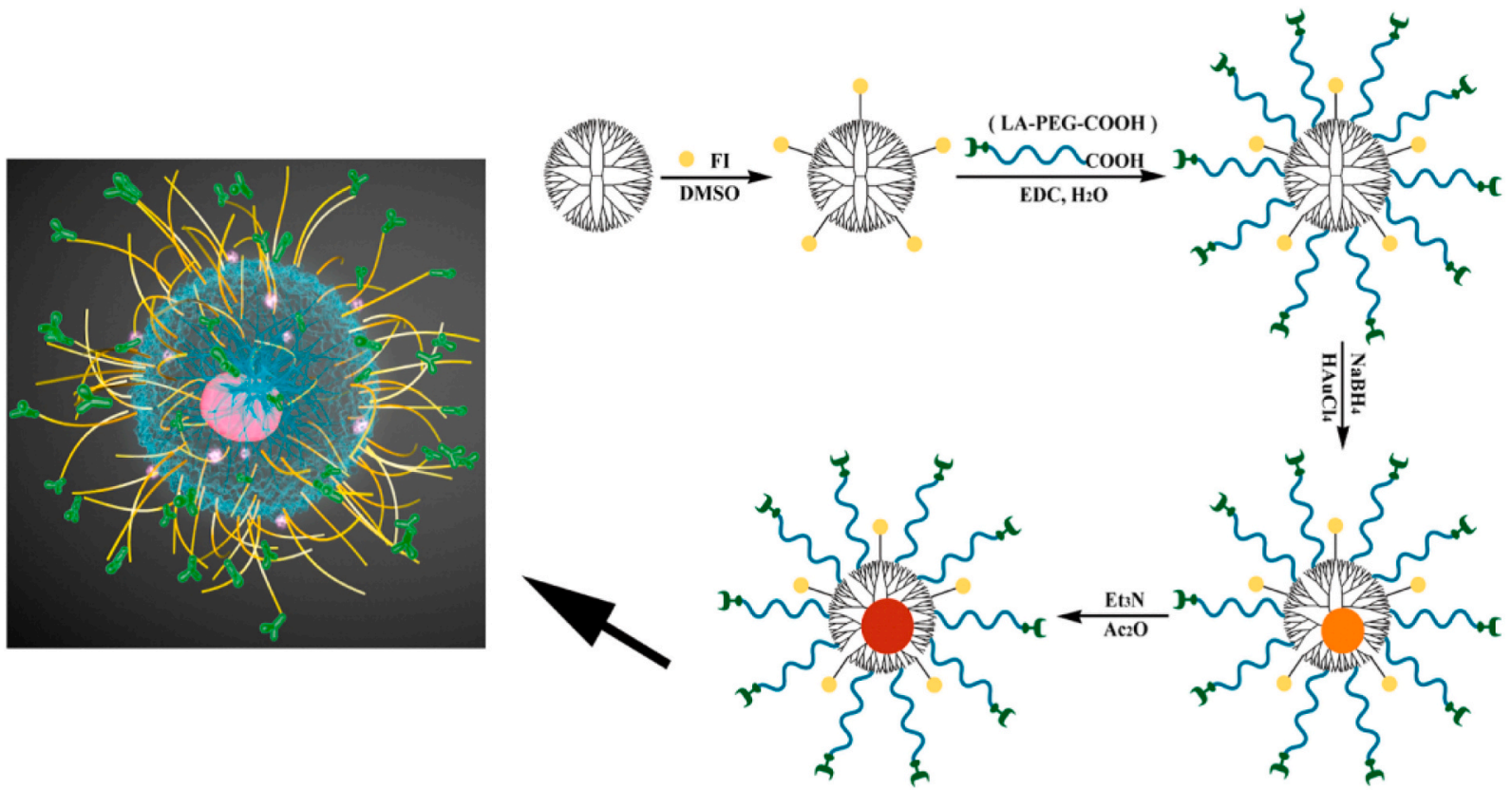

Scheme 9. Synthetic pathways for the preparation of LA-Au DENPs. Modified reproduction with permission from Ref. [105] Copyright 2020 ACS publications.

(CT) imaging applications using dendrimers as templates, as shown by Peng and Shi et al. [107], whereas FA is a well-known targeting ligand for the surface of tumor cells. The cytotoxicity and hemocompatibility of these nanoparticles were evaluated using cell viability assays, flow cytometric analysis of the cell cycle and apoptosis, and hemolytic assays. Au DENPs-FI-FA-DTA nanoparticles did not cause cytotoxic effects in HeLa tumor cells and did not affect the cell cycle distribution in HeLa cells. In vitro cellular uptake assays demonstrated specific uptake of Au DENPs-FI-FA-DTA by cervical cancer cells with high levels of FAR expression through a receptor-mediated mechanism. The identification of HeLa cervical cancer has been established by micro-CT image techniques. HeLa cervical cancer can be imaged in vivo assays of xenografts model, in BALB/c nude mice, after intravenously or intratumorally injection of DENPs-FI-FA-DTA. In another work, Shi et al. investigated the utility of (Au(0)-G5.NHAc-PAMAM-PEG DENPs) for indirect enhanced CT lymphography (CT-LG) imaging of cervical sentinel lymph nodes (SLN) in rabbits. [108]

\subsubsection{Ultrasound and radiotherapy approaches}

An important innovative strategy in oncology against difficult cancers such as pancreatic cancer ( $\mathrm{PaCa}$ ), associated with low drug permeability, poor vascularization, a dense stroma, and inherent or acquired drug resistance by classical chemotherapy, has been presented by Lin, Shi et al. [109] This strategy was based on the use of the ultrasound-targeted microbubble destruction (UTMD) technique, which promotes the co-delivery (synergistic effect) of gemcitabine (Gem), which is used in the treatment against advanced or metastatic PaCa, and miR-21 inhibitor (miR-21i) from PEGylated G5 PAMAM dendrimerentrapped gold nanoparticles affording Gem-Au DENPs/miR-21i NPs (Fig. 1).

Clearly, these studies showed that Gem-Au DENPs/miR-21i NPs can be taken up by SW1990 cancer cells, and cellular uptake profile was facilitated by UTMD technique using an ultrasound power of $0.4 \mathrm{~W} / \mathrm{cm}^{2}$, to boost the permeability of cells. Importantly, the enhanced tumor inhibition efficacy in vivo in the xenograft SW1990 tumor model in mice was also presented. The volume of tumors of treated mice were ample smaller than those of the Gem alone.

The construction of G4-PAMAM dendrimers encapsulating Au NPs, bearing ${ }^{177} \mathrm{Lu}$, and linked with FA and bombesin as two different ligands has been advocated by Mendoza-Nava and colleagues (Fig. 2). [110] The objective of this interesting radiotherapy study was to evaluate the radiopharmaceutical effect (RT), as well the contemporaneous

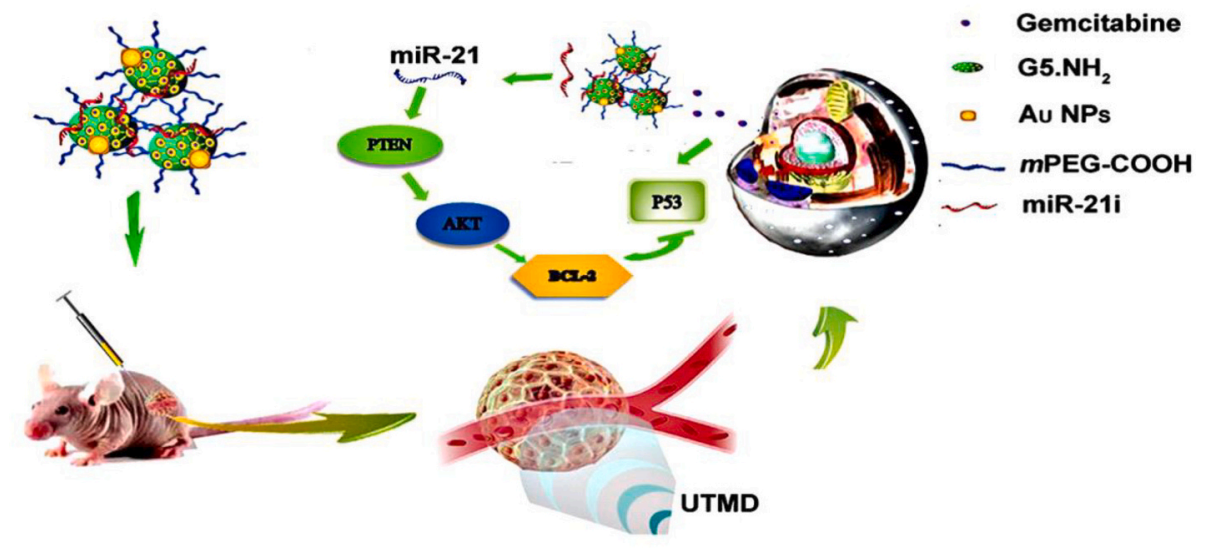

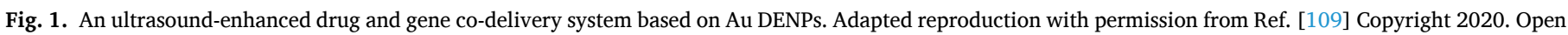
access article distributed under the terms of the Creative Commons Attribution (CC BY-NC) license. 


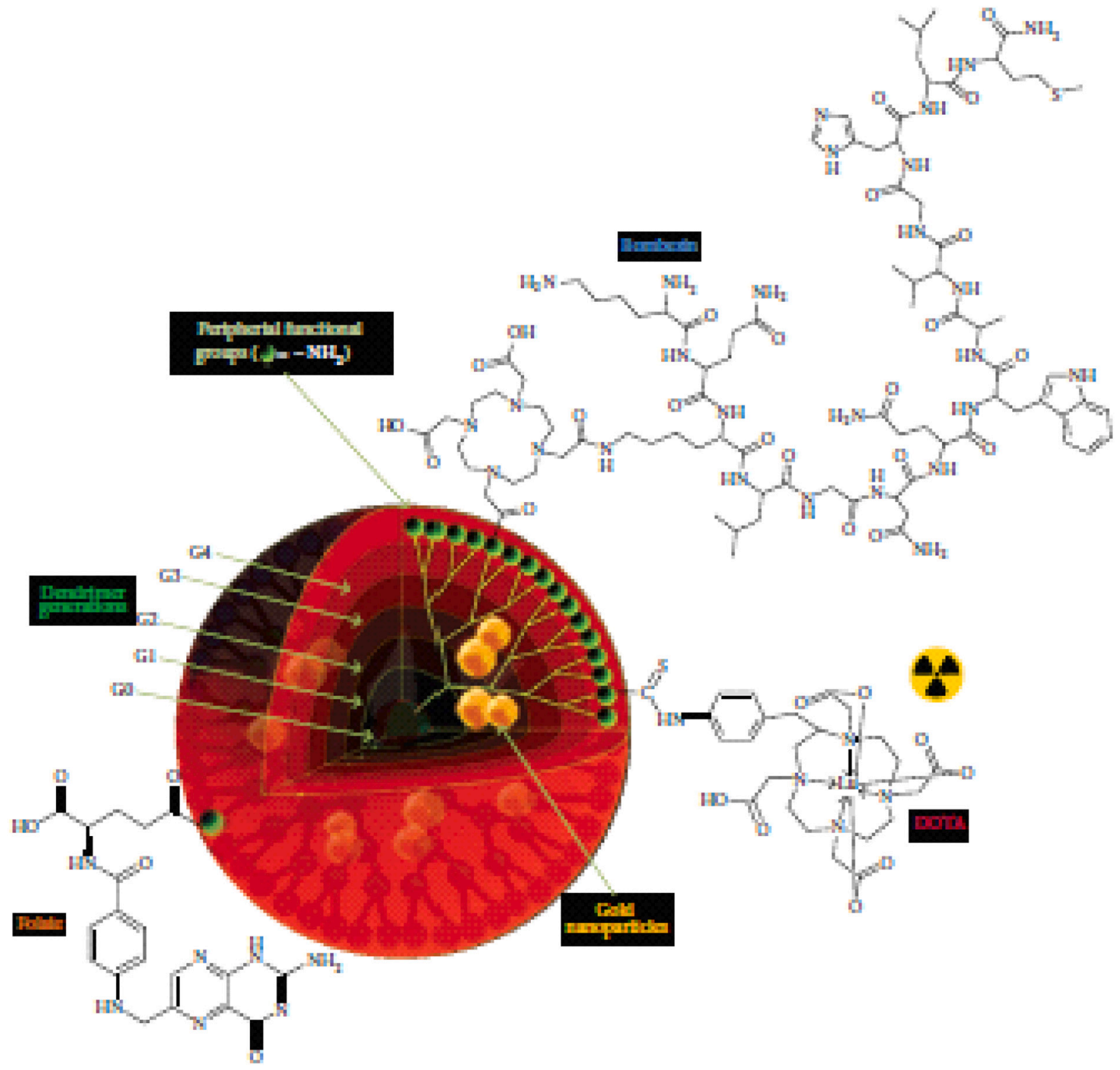

Fig. 2. 2D representation of ${ }^{177}$ Lu-DenAuNP-folate-bombesin nanoparticle. Ref. Modified reproduction with permission from Ref. [110] Copyright 2020. Open access article distributed under the terms of the Creative Commons Attribution (CC BY-NC) license.

evaluation of the expression of folate receptor (FR) and gastrin-releasing peptide receptor (GRPR) in breast cancer cells. The ${ }^{177} \mathrm{Lu}$ labeling moiety DOTA was linked to the dendrimer surface, and the incorporation of $\mathrm{Au}(0)$ was obtained through the incorporation of $\mathrm{HAuCl}_{4}$ followed by its reduction by $\mathrm{NaBH}_{4}$ (Fig. 2).

Cellular uptake showed that the ${ }^{177} \mathrm{Lu}$-DenAuNP-folate-bombesin could be specifically taken up by T47D breast cancer cells. After intratumoral injection, the ${ }^{177} \mathrm{Lu}$-DenAuNP-folate-bombesin remained at the tumor site as long as $96 \mathrm{~h}$ as demonstrated by in vivo imaging. Consequently, the ${ }^{177} \mathrm{Lu}$ dendrimer (AuNP)-folate-bombesin could be regarded as an effective imaging agent for nuclear imaging and targeted radiotherapy of GRPR- and FR-expressing breast tumors. The same authors described also the preparation and development of ${ }^{177} \mathrm{Lu}$-DOTAPAMAM-AuNP-folate-bombesin. [111]

Table 3 presents the additional studies regarding the development of dendrimer-entrapped radioactive gold nanoparticles. Recently, a review

Table 3

Examples of development of dendrimer-entrapped gold radioactive nanoparticles.

\begin{tabular}{|c|c|c|c|c|c|}
\hline Therapeutic area & $\begin{array}{l}\text { Radioactive } \\
\text { elements }\end{array}$ & Radiation types & $\begin{array}{l}\text { Dendrimers } \\
\text { used }\end{array}$ & Results & Reference \\
\hline Nanobrachytherapy of mouse melanoma tumors & ${ }^{98} \mathrm{Au}(0)$ & $\begin{array}{l}\gamma \text {-radiation and } \\
\text { neutron radiation }\end{array}$ & G5-PAMAM & $\begin{array}{l}\text { Inhibition of tumor growth ( } 45 \%) \text { after } \\
\text { intratumoral injection of NPs }\end{array}$ & [113] \\
\hline $\begin{array}{l}\text { In vitro cytotoxicity effects against } 4 \mathrm{~T} 1 \text { and MCF7 breast } \\
\text { adenocarcinoma cancer cells and } \mathrm{C} 2 \mathrm{C} 12 \text { normal cells }\end{array}$ & $\begin{array}{l}{ }^{198} \mathrm{Au}\left(\mathrm{t}_{1 / 2}=\right. \\
2.69 \text { days })\end{array}$ & $\gamma$-radiation & G4-PAMAM & $\begin{array}{l}\text { Inhibition of tumor growth of breast cancer } \\
\text { cells } \\
\text { The toxicity of }{ }^{198} \mathrm{Au} / \mathrm{PAMAMG} 4 \text { is higher } \\
\text { against cancerous cells compared to normal } \\
\text { cells }\end{array}$ & [114] \\
\hline
\end{tabular}


highlighting the use of radiolabeled dendrimers for nuclear medicine applications was published by Zhao and colleagues. [112]

\subsection{Au DENPs: gene delivery}

It is well-described that polycationic polymers in general and dendrimers in particular can be used as vectors for gene delivery, for instance of small interfering DNA (siRNA) by anionic DNA interactions with polycationic nanomaterials. [115]

Qiu, Shi and colleagues [116] developed safe and effective $\beta$-cyclodextrin $(\beta-C D)$-modified Au DENPs (Au DENPs- $\beta$-CD) for the delivery of two different siRNAs to U87MG glioblastoma cells (Fig. 3). Beta-cell lymphoma/leukemia-2 (Bcl-2) siRNA and vascular endothelial growth factor (VEGF) siRNA were selected. Once complexed with the siRNA, the AuNPs displayed good cytocompatibility. Flow cytometry and confocal microscopic observations revealed that these two siRNAs were able to be respectively transfected at the vector/siRNA polyplex N/P ratio (molar ratio of dendrimer terminal amine/siRNA phosphate) of 5:1. Further Western blot assays demonstrated that the Bcl-2 and VEGF protein expression in the transfected cancer cells were able to be significantly knocked down.

Further work by the same team developed the $\left\{\left(\mathrm{Au}^{0}\right)_{50^{-}} \mathrm{G} 5 . \mathrm{NH}_{2^{-}}\right.$ $m$ PEG2K\} DENPs for the delivery of pDNA or siRNA for in vitro gene transfection into HeLa cells. Partially PEGylated Au DENPs were used [117]. The pDNA encoding luciferase (Luc) or enhanced green fluorescent protein (EGFP) and Bcl-2 siRNA were employed. The developed $\left\{\left(\mathrm{Au}^{0}\right)_{50}-\mathrm{G} 5 . \mathrm{NH}_{2}-\mathrm{mPEG} 2 \mathrm{~K}\right\}$ DENPs enabled significant Luc and EGFP expression within the cancer cells or knocked down the Bcl-2 protein expression with the DNA or siRNA delivery efficiency significantly higher than $\mathrm{G} 5 . \mathrm{NH}_{2}$ or PEGylated G5. $\mathrm{NH}_{2}$ dendrimers without Au. The PEGylated Au DENPs had a maximum Luc transfection efficiency around 292 times higher than the G5. $\mathrm{NH}_{2}$ dendrimers, and enabled $85 \% \mathrm{Bcl}-2$ gene silencing efficiency when compared to the $\mathrm{G} 5 . \mathrm{NH}_{2}$ dendrimers under the same respective conditions.

In the same direction, an original approach based on the serum gene delivery [118] of zwitterionic dendrimers encapsulating gold nanoparticles (Au DENPs) to inhibit in vitro cancer cell metastasis, has been published by Xiong et al. [119] In order to avoid the interactions between serum protein and cationic vector and gene polyplexes inducing a significant reduction in cellular uptake efficiency, novel systems were developed. As shown in Scheme 10, G5 PAMAM dendrimers have been functionalized, on its surface, with both zwitterionic carboxybetaine acrylamide (CBAA) and morpholine (Mor) as lysosome-targeting agent. The final biocompatible nanodevice $\left\{\left(\mathrm{Au}^{0}\right)_{25}-\mathrm{G} 5 . \mathrm{NH}_{2}\right.$-PEG-Mor $\}$ NPs with a N/P value of 0.5 or above, displayed effective delivery of HIC1 gene which inhibits cancer cell metastasis.

Another study has been described by Mbatha and colleagues regarding the synthesis, characterization, cytotoxicity profile, and in vitro gene delivery ability of reporter plasmid DNA containing a Luc gene (pCMV-Luc DNA) to various mammalian cancer cells by FA-modified G5 PAMAM dendrimer encapsulating AuNPs to give Au:G5D:FA NPs with a $\mathrm{Au} /$ dendrimer ratio of 25:1 (Scheme 11). [120]

The complexation of Au:G5D:FA NPs with pCMV-Luc DNA was characterized by several techniques including transmission electron microscopy, nanoparticle tracking analysis, ultraviolet spectroscopy, nuclear magnetic resonance, band shift, dye displacement, and nuclease protection assays. The NPs (Au, G5D, Au:G5D and G5D:FA) showed spherical shape, regular distribution with diameter ranking between 65 and $128 \mathrm{~nm}$, whereas Au:G5D:FA, Au:G5D:FA-pDNA ( $w / w$ NP/DNA ratio $=5.2: 1)$, and Au:G5D:FA-pDNA $(W / \mathrm{W}$ NP/DNA ratio $=6.0: 1)$ displayed a mean diameter of $77.7 \mathrm{~nm}, 248 \mathrm{~nm}$, and $112 \mathrm{~nm}$, respectively. The zeta potential of NPs, without pDNA, showed a value between +21 and $+87 \mathrm{mV}$, whereas NPs with pDNA showed values between -20 and $-38 \mathrm{mV}$. MTT cell viability assays were performed against four mammalian cancer cell lines (human liver carcinoma HepG2, human epithelial colorectal adenocarcinoma Caco-2, breast cancer MCF-7, and epidermal carcinoma of the mouth KB cells) and one non-cancer cell line (HEK293). Interestingly, for all ratios studied, significative cell viabilities (70\%-97\%) were observed with Au:G5D: DNA and Au:G5D:FA:DNA NPs in the HEK293, HepG2, and Caco-2 cell lines versus G5D:DNA and G5D:FA:DNA NPs (60-89\%). Consequently, Au:G5D:DNA and Au:G5D:FA:DNA nanocomplexes were found to be slighter cytotoxic than the G5D:DNA and G5D:FA:DNA nanocomplexes and may be safe to use in therapeutic applications. Au:G5D:FA:DNA nanocomplexes seemed to be the least toxic over Au:G5D:DNA nanocomplexes. Transfection studies demonstrated that the transgene expression was higher with grafted gold NPs with FA in FARoverexpressing cells, compared to that of the control dendrimer

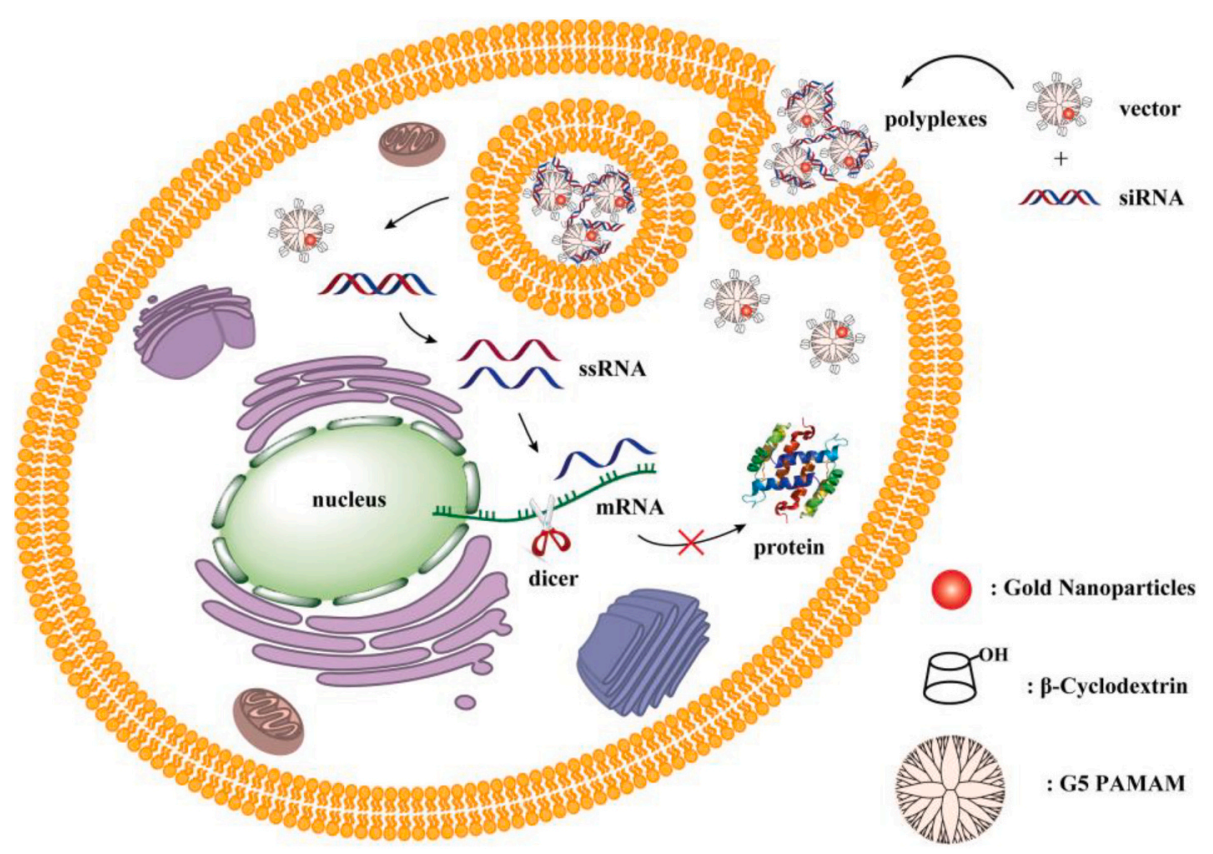

Fig. 3. Global view of the cellular delivery process of genes using Au DENPs- $\beta$-CD/siRNA polyplexes. Modified reproduction with permission from Ref. [116] Copyright 2020. Open access article MDPI. 


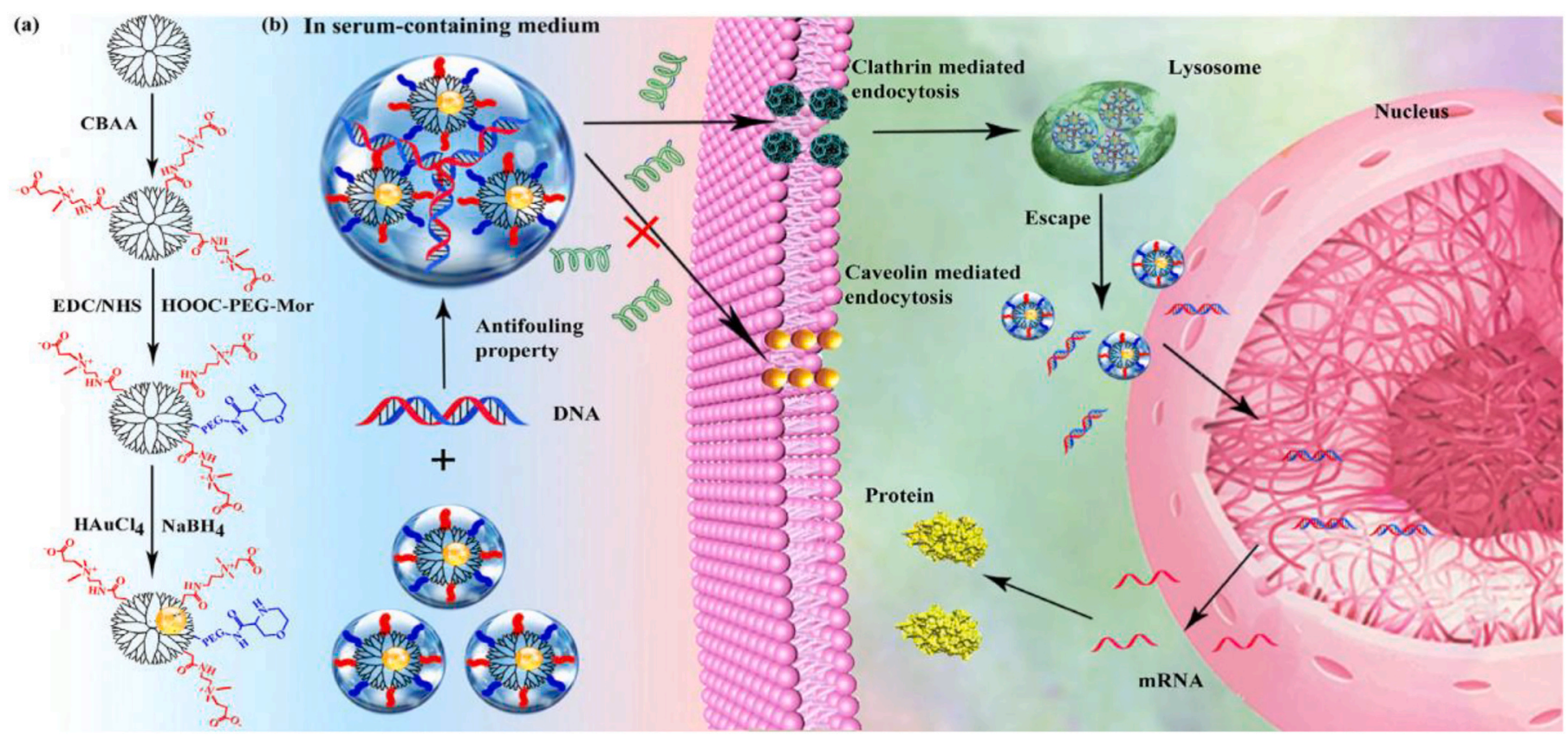

Scheme 10. Schematic description of the preparation of $\left\{\left(\mathrm{Au}^{0}\right)_{25}\right.$-G5-CBAA-PEG-Mor $\}$ DENPs. For the abbreviations, see text. Reproduced with permission from Ref. [119] Copyright 2020. Elsevier.

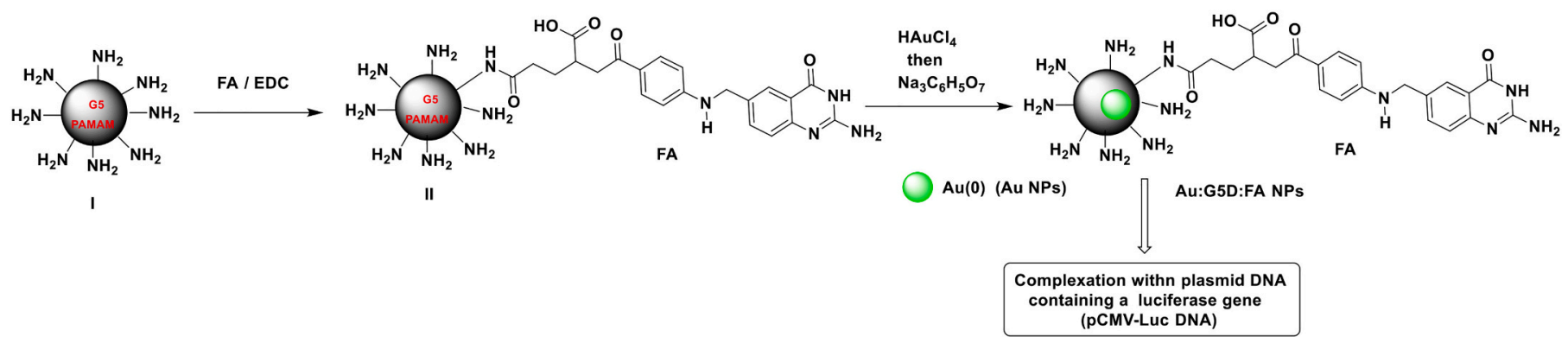

Scheme 11. Schematic representation of the preparation of Au:G5D:FA NPs.

nanoparticles. In HEK293, HepG2, and Caco-2 cells, the transfection expression levels were lower than those observed in MCF-7 and KB cells which are FAR positive tumor cell lines. Au:G5D:DNA and Au:G5D:FA: DNA NPs showed the highest transfection levels versus NPs without entrapped gold, such as G5D:DNA and G5D:FA:DNA. Similarly, the same authors described the development of an siRNA complexed with Au:G5D and Au:G5D:FA NPs for delivery to HeLa-Tat-Luc cells. [121]

\subsection{Au DENPs: drug delivery}

Elegantly, Shi et al. proposed a new pH-responsive theranostic nanoplatform with Au entrapped for CT imaging and chemotherapy of tumor cells [122]. In this work, G5 PAMAM dendrimers were partly acetylated, and then sequentially linked with FA and DOX to form G5.NHAc-FA-DOX conjugates for final entrapment of AuNPs (Scheme 12). The research team demonstrates that the created DOX-Au DENPs possess an Au core size of $2.8 \mathrm{~nm}$ and 9.0 DOX moieties per dendrimer, and present good colloidal stability. Furthermore, due to the $\mathrm{pH}$ responsive cis-aconityl linkage, the DOX-Au DENPs release DOX much faster under an acidic $\mathrm{pH}$ than under the physiological $\mathrm{pH}$. Additionally, the DOX-Au DENPs presented a much greater X-ray absorption coefficient than Omnipaque ${ }^{\mathrm{TM}}$. These properties rendered the DOX-loaded $\mathrm{Au}$ DENPs with performances for targeted CT imaging/chemotherapy of cancer cells which overexpress FA receptors.
Notably, Alibolandi et al. presented an interesting study about a biomedical application in the theranostic domain of a multifunctional curcumin-entrapped MUC-1 DNA aptamer targeted PEGylated (3500) G5 PAMAM dendrimer-gold hybrid nanoplatform for CT imaging purpose. The MUC-1 aptamer was conjugated to the dendrimer to target human colon adenocarcinoma HT29 cells, mouse colon adenocarcinoma C26 cells, and Chinese hamster ovary (CHO cells) in vitro and in vivo. [123] Both AuNP and curcumin (CUR), as natural polyphenol anticancer agent, were entrapped in the G5 PAMAM dendrimer. This nanoplatform avoided for CUR the low water solubility, biodisponibility, and strong global clearance. The selectivity of the gold effect of curcumin delivery was ensured by the presence of the attached MUC-1 DNA aptamer with the sequence: 5'-thiol-C6 linker-GCAGTTGATCCTTTGGATACCCTGGTTTTTTTTTT-3, which targets MUC-1 receptors overexpressed in several tumor cells including colorectal, breast, prostate carcinoma, and lymphocytic leukemia. [124] The unmodified G5 PAMAM dendrimer had a zeta potential of $37.6 \mathrm{mV}$, whereas the PEGylated G5 PAMAM dendrimer showed a zeta potential of $8.2 \mathrm{mV}$ in the presence of AuNPs over $4.6 \mathrm{mV}$ in the presence of the conjugated MUC-1 DNA aptamer. Cellular uptake assays using flow cytometry showed higher cellular uptake of the MUC-1-PEG-AuPAMAM-CUR formulation versus PEGAuPAMAM-CUR formulation in HT29 cells. This effect resulted in the high affinity of the MUC-1 DNA aptamer for the MUC-1 protein on the surface of HT29 cells. In contrast, the MUC-1- 


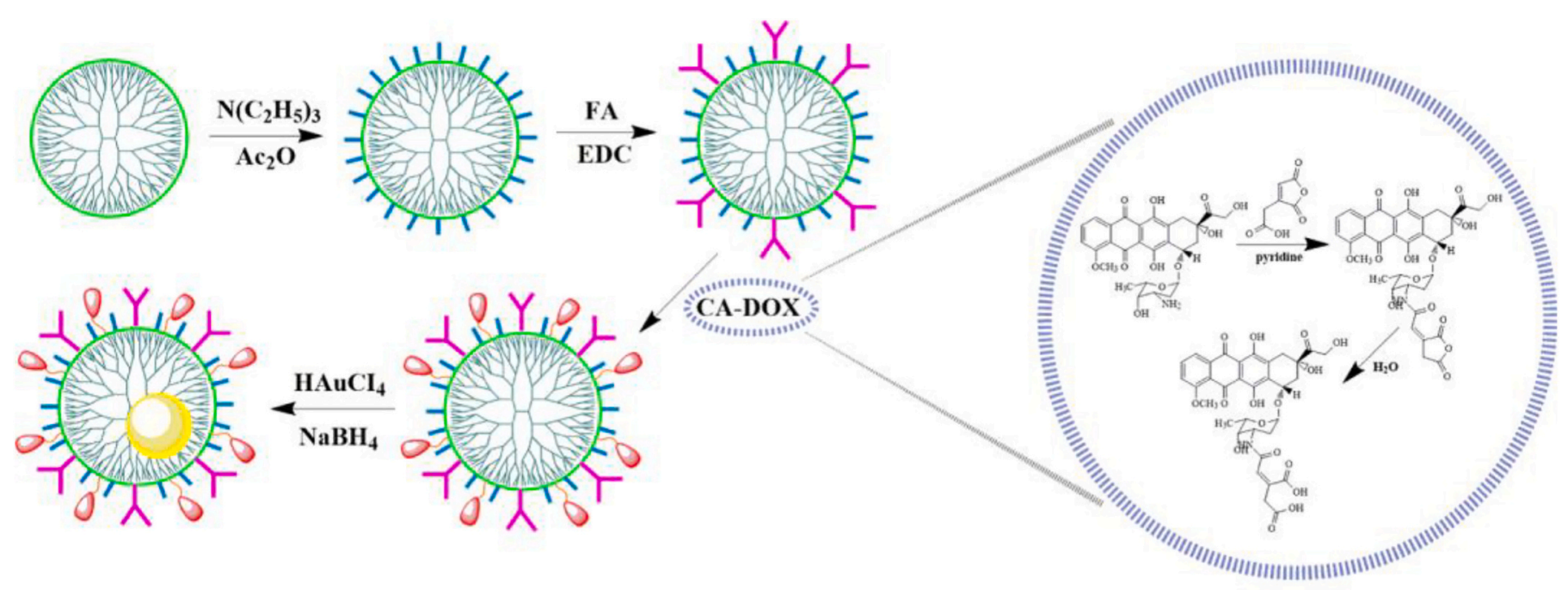

$$
\text { Ac: / FA:Y DOX:O CA-DOX : } \quad \text { Au NPs : }
$$

Scheme 12. Illustration of the synthesis for the $\mathrm{pH}$ responsive theranostic nanoplatforms with Au encapsulating \{(Au0)50-G5.NHAc-FA-DOX\} (in short DOX-Au DENPs) Modified reproduction with permission from Ref. [122] Copyright 2020 ACS publications.

PEG-AuPAMAM-CUR and PEGAuPAMAM-CUR formulations showed the same uptake levels in the CHO cell line without MUC-1 expression. Cytoxicity studies of Apt-PEG-AuPAMAM-CUR, PEGAuPAMAM-CUR and curcumin were determined in two MUC-1 positive cell lines (HT29 and $\mathrm{C} 26$ ) and a MUC-1 negative cell line (CHO). Curcumin induced greater cytotoxicity than PEG-AuPAMAM-CUR in the HT29 and C26 cell lines. Apt-PEG-AuPAMAM-CUR formulation induced more cytotoxicity in the HT29 and C26 cell lines than PEG-AuPAMAM-CUR formulation without targeting moieties, demonstrating the crucial role of the MUC-1 DNA targeting effect. PEG-AuPAMAM-CUR and Apt-PEGAuPAMAMCUR did not displayed significant cytotoxicity in MUC-1 negative CHO cell line. In addition, an in vivo study was performed by the subcutaneous implantation of C26 mouse colorectal adenocarcinoma in Balb/C mice. The analysis of tumor growth inhibition, at a dose of $5 \mathrm{mg} / \mathrm{kg}$ iv administration twice during 30 days, showed greater efficacy of AptPEG-AuPAMAM-CUR over PEG-AuPAMAM-CUR, as well as greater efficacy than curcumin alone or PEG-Au-PAMAM. EPR effect can explain the higher therapeutic profile of PEG-AuPAMAM-CUR versus CUR alone.

A noticeable study has been described by Wang et al. about the design and development of G3-G5 hydroxyl-terminated PAMAM AuNPs for glutathione(GSH)-responsive thiolated DOX and cisplatin drug delivery nanosystems. [125] Also, based on the same strategy, captopril (an antihypertensive drug) and 6-mercaptopurine (an antileukemic drug) were covalently linked to AuNPs (Fig. 4). In this system, GSH played the role of a specific trigger (Scheme 13). The drug molecules were covalently linked with $\mathrm{Au}$ through $\mathrm{Au}-\mathrm{S}$ linkages within the voided space of the dendrimer. The shape of G5 HO-PAMAM:Au NPs was globular form with a size around $3 \mathrm{~nm}$.

After $3 \mathrm{~h}$, captopril was released from G5-HO-PAMAM in PBS, while $\sim 18 \%$ of captopril was observed at $12 \mathrm{~h}$ with G5-HO-PAMAM:Au NPs. In PBS buffer, about $17 \%$ of 6-mercaptopurine conjugated with G5-OHPAMAM:Au NPs was delivered at $24 \mathrm{~h}$. Most of the tested drugs were released from G5-OH and G5-NH2 dendrimers within $2 \mathrm{~h}$ period of time. Thiolated DOX (DOX-SH) conjugated with G5-OH:Au NPs demonstrated a decrease of cytotoxicity in the HeLa cervical cancer cell line versus DOX-SH alone. Similarly, cisplatin-SH loaded with G5-OH:Au NPs displayed a decrease of cytotoxicity in contrast to cisplatin-SH molecules in the HeLa, osteosarcoma U2OS, and breast MCF-7 tumor cell lines. Flow cytometry and confocal laser scanning microscopy studies, in HeLa cancer cells, demonstrated that the release of DOX-SH NPs results of glutathione effect.

In summary, Doxorubicin, doxorubicin-SH, curcumin, 6-mercaptopurine, captopril and cis-platin SH were delivered using Au DENPs.

Besides the use of Au DENPs for CT imaging, attempts have also been directed to the use of Au DENPs for photothermal therapy. For instance, Kono et al. [126] used poly(ethylene glycol) (PEG)-modified generation 4 (G4) poly(amidoamine) (PAMAM) dendrimers to entrap Au NPs, and found the formed Au DENPs possessed light-induced heat generation ability. However, due to the small Au core size ( $2 \mathrm{~nm}$ ), the Au DENPs only displayed limited photothermal conversion efficiency, which is inadequate for further photothermal therapy (PTT) applications. In order to overcome this issue, dendrimer-stabilized Au NPs with a size around $30 \mathrm{~nm}$ [127] or dendrimer-stabilized Au nanorods [128] have been used for PTT of tumors. However, in this case, the dendrimer-

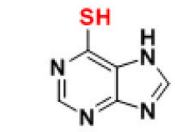

6-mercaptopurine

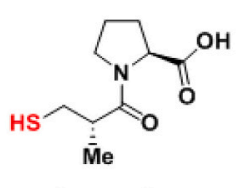

Captopril

Fig. 4. Representation of chemical Structures of thiol-containing (captopril and 6-mercaptopurine) and thiolated drugs (DOX and cisplatin). 


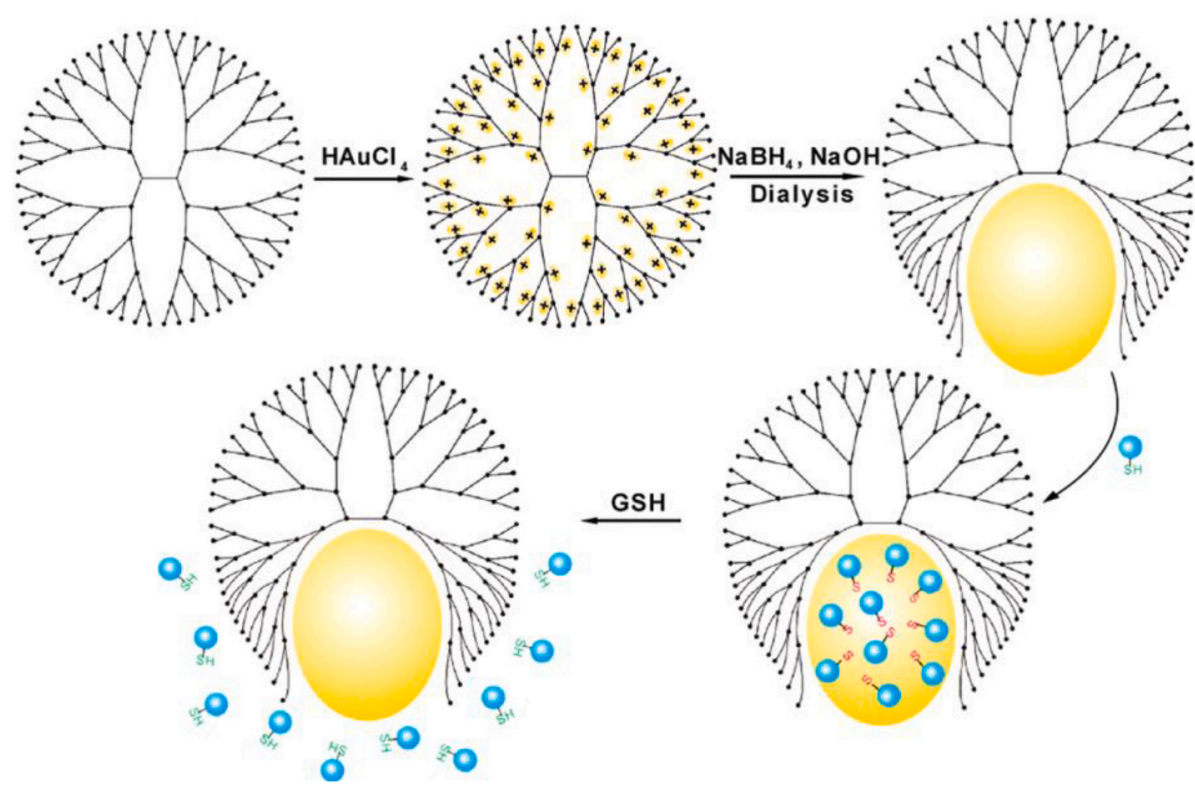

Scheme 13. Schematic preparation of G5 HO-PAMAM:Au NPs and drug release principle using GSH Modified reproduction with permission from Ref. [125] Copyright 2020 ACS publications.

associated Au NPs no longer belong to the category of Au DENPs.

3. Dendrimer/dendron-complexed gold(III) nanoparticles: technologies to take down cancer cells

Majoral and Mignani were pioneers in the development of

1G3-phosphorus dendrimers

(48 terminal groups)

1G3: $X=$ nothing

1G3-Cu(II): $\mathrm{X}=\mathrm{CuCl}_{2}$

1G3-Au(III): $\mathrm{X}=\mathrm{AuCl}_{2}^{+}: \mathrm{AuCl}_{4}^{-}$

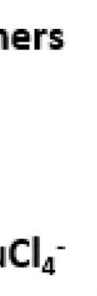

$\sqrt{3}$
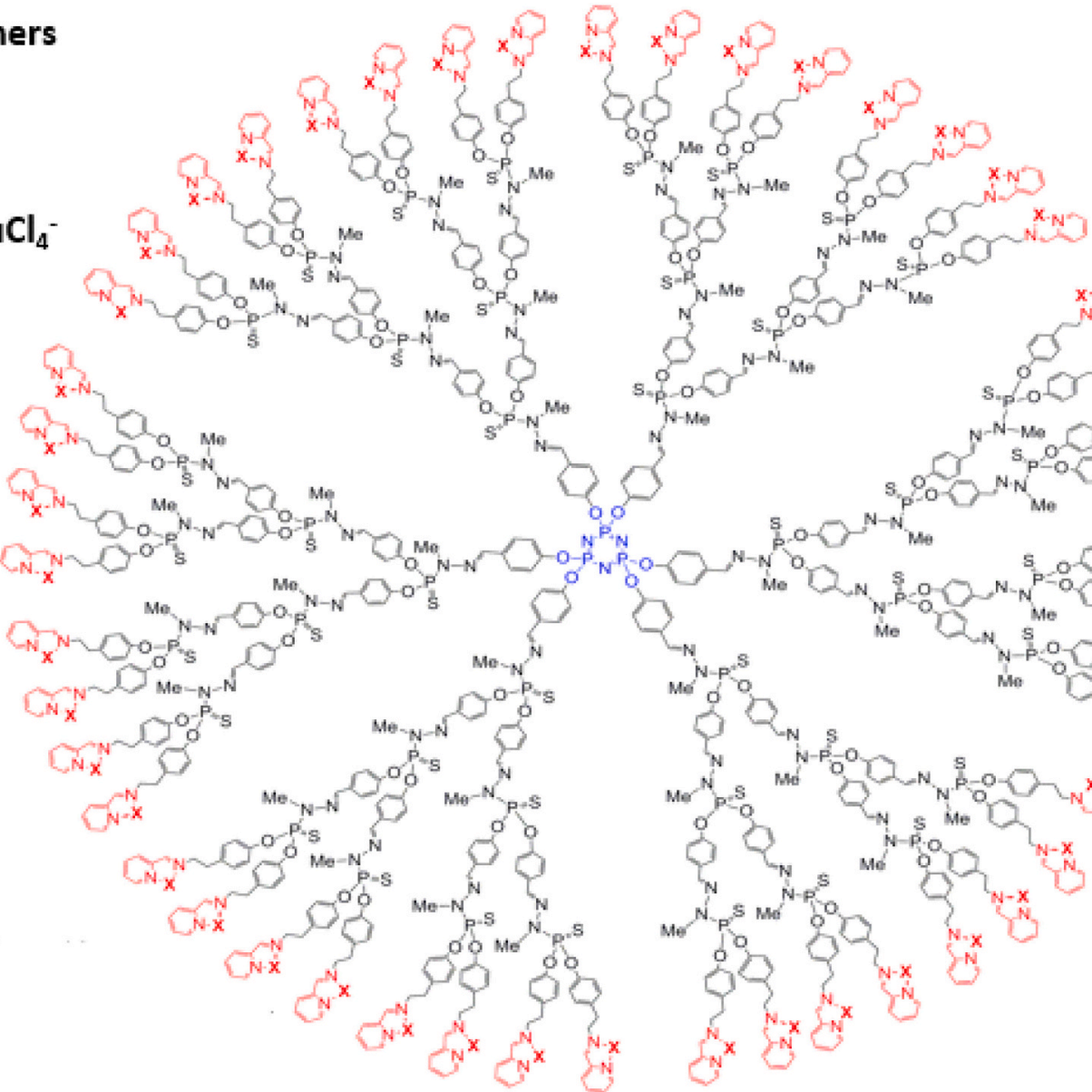

N-Me

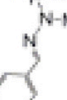

3
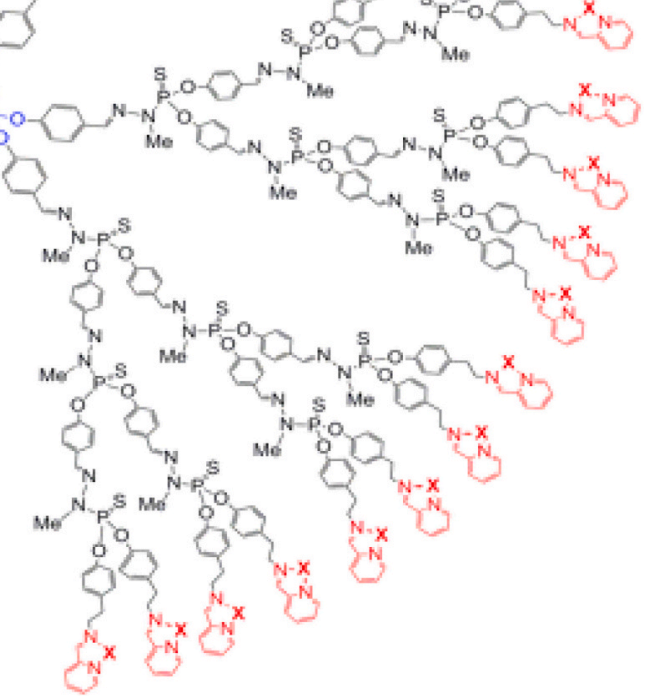

Fig. 5. 2D chemical structure of 1G3-Cu(II) and 1G3-Au(III). 
dendrimer-complexed gold(III) nanoparticles to take down tumor cells. Biocompatible phosphorus dendrimers were selected as templates. In the cancer chemotherapy field, cisplatin, oxaliplatin, carboplatin, and Pt (IV) complexes as prodrugs are usually used, but with main drawbacks encompassing resistance and severe toxicity. In addition, other metal complexes to tackle tumors have been developed including, $\mathrm{Ru}(\mathrm{II} / \mathrm{III})-$, Au(I/III)-, Ga(III)-, Ti(IV)-, V(IV/V)-, Cu(I/II)-, Fe(II/III)-, and Zn(II)based complexes. [129]

Firstly, Majoral et al. reported the drawing and synthesis of biocompatible first-in-class multivalent $\mathrm{Cu}(\mathrm{II})$-conjugated phosphorus dendrimers with a cyclotriphosphazene ring as core and $\mathrm{Cu}(\mathrm{II})$ chelating agents such as $N$-(pyridin-2-ylmethylene)ethanamine (called NN), N-(di (pyridin-2-yl)methylene) ethanamine, and 2-(2-methylenehydrazinyl) pyridine, with several generations (1-3). Based on the phenotypic approach, the phosphorus dendrimer of generation 3, with an $\mathrm{N}$-(pyridin-2-ylmethylene)ethanamine chelating group complexing $\mathrm{Cu}(\mathrm{II})$ (called 1G3-Cu, with 48 metallic moieties on the surface; Fig. 5) displayed the highest anti-proliferative efficiency against the epidermal carcinoma KB and leukemia, promyelocytic HL60 tumor cell lines with $\mathrm{IC}_{50} \mathrm{~S} \sim 0.5-2 \mu \mathrm{M}$. Note that the G3-phosphorus dendrimer with the N,N chelating group without $\mathrm{Cu}(\mathrm{II})$ (called 1G3) also showed interesting antiproliferative activity but with higher $\mathrm{IC}_{50} \mathrm{~s} \sim 0.4-1.3 \mu \mathrm{M}$. [130,131] 1G3-Cu and 1G3 showed similar antiproliferative activities versus a panel of tumor cells such as HCT 116 (human colon cancer), OVCAR8 (ovarian carcinoma), MCF7 (hormone-responsive breast cancer), and U87 (human glioblastoma astrocytoma epithelia-like) with $\mathrm{IC}_{50} \mathrm{~s} \sim$ $0.3-0.8 \mu \mathrm{M})$.

Remarkably, the complexation with $\mathrm{Cu}(\mathrm{II})$ of the terminal ligands NN (1G3-Cu) strongly intensified the $\mathrm{IC}_{50}$ values ( 4-10-fold) in normal cell lines such as EPC (endothelial progenitor, Cyprinus carpio) and MCR5 (proliferative human lung fibroblasts) referred to as "safety" cell lines. Investigation of the mechanism of action of 1G3-Cu and 1G3 showed that they induced cell death through the activation of the apoptosis process. Very interestingly, the pro-apoptotic Bax protein was highly activated by $1 \mathrm{G} 3-\mathrm{Cu}$ and translocated to the mitochondrial compartment. Then the release of apoptosis inducing factor (AIF), and finally the activation of the caspase-independent apoptosis process were observed.

Then, based on these very interesting results, the same team turned to the development of original G3 phosphorus dendrimer-complexed gold(III) nanoparticles (called 1G3-Au(III)) as anticancer agents. The anti-proliferative activities of $1 \mathrm{G} 3-\mathrm{Cu}(\mathrm{II})\left(1 \mathrm{G} 3-\left[\mathrm{CuCl}_{2}\right]_{48}\right)$ and $1 \mathrm{G} 3-\mathrm{Au}$ (III) (1G3-[ $\left[\mathrm{Au}_{48}\right]\left[\mathrm{AuCl}_{4}\right]_{48}$; Fig. 18) as well the safety ratio are presented in Fig. 6. [73,74] The exact structure of the gold(III) complex on the surface of G3 phosphorus dendrimers was determined by the X-ray structure of the $\mathrm{Au}(\mathrm{III})$-monomer complex 1 (Fig. 7). The complexation of the $\mathrm{G} 3$ phosphorus dendrimer with $\mathrm{Au}(\mathrm{III})$ in place of $\mathrm{Cu}(\mathrm{II})$ strongly increased the antiproliferative activity against both the KB and HL-60 tumoral cell lines, showing $\mathrm{IC}_{50} \mathrm{~s}$ in the low nanomolar range. Gold (III) conjugated phosphorus dendrimers showed low activity on the quiescent cell line EPC versus its potent antiproliferative activity against actively dividing cells, indicating a good safety ratio. The same results were obtained but to a lesser degree against the MRC5 cell line.

The next study was the analyze of the influence of the distribution of the two metal moieties $\mathrm{Cu}(\mathrm{II})$ and $\mathrm{Au}(\mathrm{III})$ on the surface of $1 \mathrm{G} 3$ dendrimers, bearing a total of 48 groups on the surface, on the cytotoxicity effects against the KB and HL60 tumor cell lines, as well quiescent EPC cell line. [132] As show in Fig. 8, nine bimetallic $\mathrm{Cu}(\mathrm{II}) / \mathrm{Au}(\mathrm{III})$ dendrimers were prepared and compared to the two monometallic phosphorus dendrimers 1G3-Au and 1G3-Cu. NN was the $N$-(pyridin-2ylmethylene)ethanamine chelating group located on the surface of G3 dendrimer, and PEG was a $\mathrm{C}_{11}$ polyethylene glycol chain.

Fig. 9 shows the anti-proliferative activities of the eleven mono and bimetallic phosphorus dendrimers against the KB and HL60 tumor cell lines. Interestingly, none of the dendrimers displayed activity against the quiescent EPC cell line $\left(\mathrm{IC}_{50} \mathrm{~s}>1000 \mathrm{nM}\right.$ ), and similar potency (nanomolar range) as $\mathbf{1 G 3}-\left[\mathrm{Au}_{48}\right]\left[\mathrm{AuCl}_{4}\right]_{48}$ against $\mathrm{KB}$ and $\mathrm{HL60}$ cells was obtained for any bimetallic phosphorus dendrimers bearing gold (III) units, whatever the ratio.

In addition, 1G3-Au and 1G3-PEG/Au(9) showed good anti-cancer activities against other tumor cell lines such as MCF7 human breast adenocarcinoma cell line and PC3 prostatic small cell carcinoma $\left(\mathrm{IC}_{50} \mathrm{~S}\right.$ 0.5-2.5 nM), whereas 1G3-PEG/Au/Cu(7) displayed IC $_{50}$ s of 60 and 13 $\mathrm{nM}$ against MCF7 and PC3, respectively.

Based on the strong collaboration between Majoral, Mignani, and Shi, the development of potent anticancer G1 phosphorus dendrons, bearing $\mathrm{Cu}(\mathrm{II})$ and $\mathrm{Au}(\mathrm{III})$ units, has been achieved (Fig. 10). [133] These metaled dendrons exhibited significant antiproliferative activity versus aggressive breast cancer cell lines such as $4 \mathrm{~T} 1$ mouse breast adenocarcinoma cells $4 \mathrm{~T} 1$ which are highly tumorigenic and invasive tumor cell lines, and MCF-7 human breast adenocarcinoma cells. The safety aspect of these dendrons was evaluated using fibroblast NIH-3 T3 cells and human fetal lung fibroblast MRC5 cells (Fig. 11).

As shown in Fig. 11, the antiproliferative activity of 1GC11-Cu(II) was better than that of 1GC17-Cu(II) against both 4 T1 and MCF-7 cells with $\mathrm{IC}_{50 \mathrm{~S}} \sim 0.6-1.5 \mu \mathrm{M}$ over $\sim 1-2.7 \mu \mathrm{M}$, respectively. These two metaled dendrons displayed safety ratios between 2.5 and 4 .

\section{Antiproliferative activities}

\section{Safety ratio}

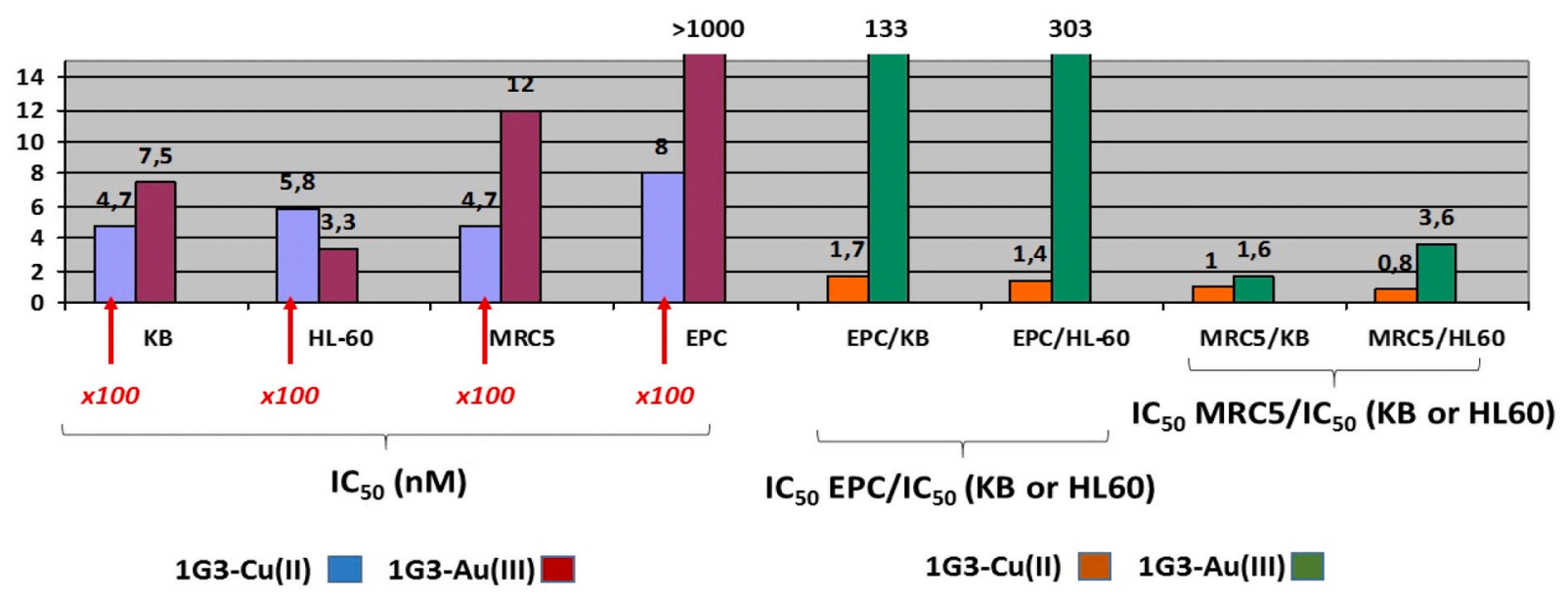

Fig. 6. The anti-proliferative activities and safety ratio of $1 \mathrm{G} 3-\mathrm{Cu}(\mathrm{II})$ and $1 \mathrm{G} 3-\mathrm{Au}(\mathrm{III})$. 


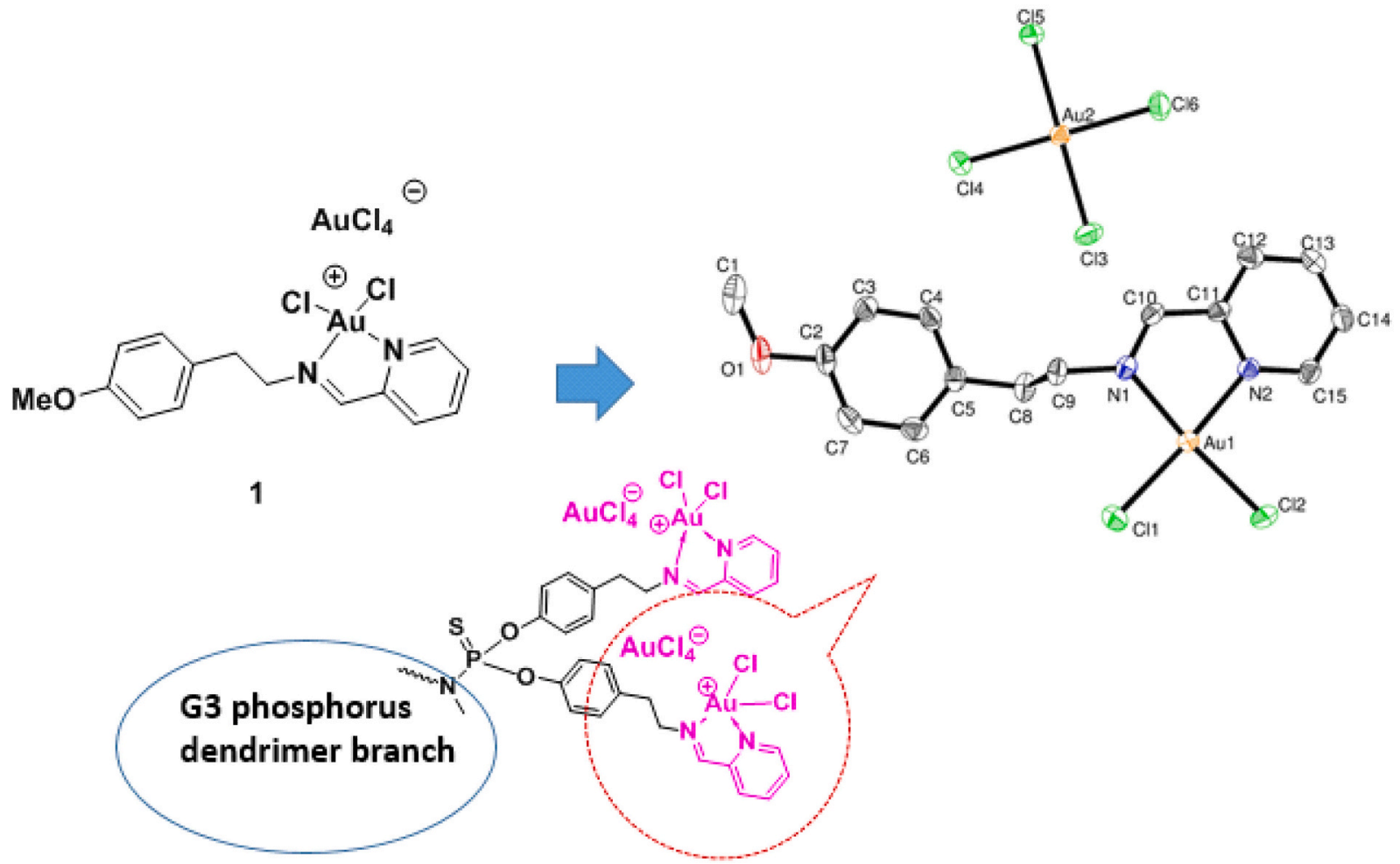

Fig. 7. Chemical structure and X-ray structure of the Au(III)-monomer complex 1. See Fig. 18 for full representation of the phosphorus dendrimer.

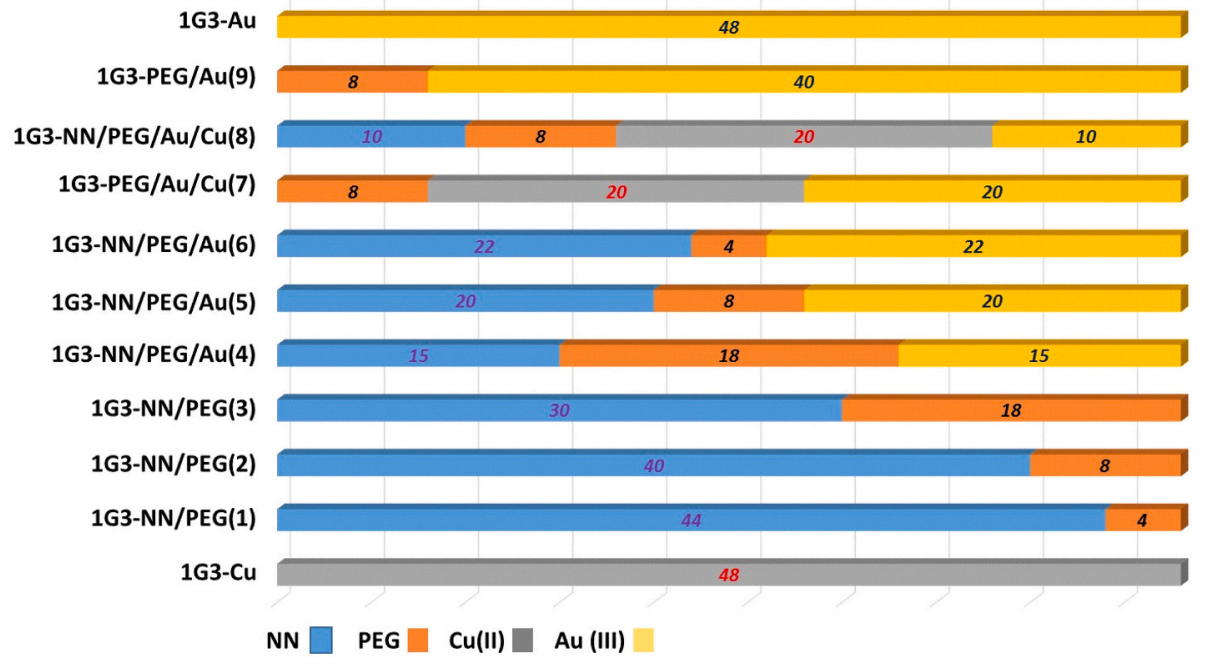

Fig. 8. Metal surface distribution of prepared metaled and non-metaled phosphorus dendrimers.

\section{Conclusion and future directions}

There are many types of cancer treatments, and nanomedicine is part of this strategy. [134] One of the main challenges in nanomedicine is to increase delivery efficiency to the tumor, which is typically less than $1 \%$. [135] Within the nanotechnology domain, a theranostic strategy has been developed to treat cancers. Promising theranostic agents/tools include metal nanoparticles, such as iron, gold, silver, zinc, and titanium, as these play crucial dual roles as 1) diagnostic and 2) active therapeutic agents to take down cancers. This original review highlights the development of functionalized dendrimer encapsulating gold nanoparticles as a novel class of theranostic (radio)pharmaceutical in cancer therapy. Several techniques were described and analyzed including 1) dendrimer-entrapped gold(0) hybrid nanoparticles for targeted imaging and treatment, 2) Au DENPs for gene and drug delivery applications, 3) dendrimer-entrapped gold radioactive nanoparticles for radiotherapy, and 4) dendrimer-complexed gold(III) nanoparticles as technologies to attack cancer cells. One of interesting and promising directions in the theranostic field is to develop stable and biocompatible non-invasive functionalized dendrimer-entrapped gold nanoparticles (AuNPs). Dendrimers have been used as both templates and nanoreactor hosts to engender $\mathrm{Au}(0)$ inside the cavities of dendrimers. Specific functionalizations (e.g. PEG chains, acetylation of terminal amino groups, introduction of a targeting ligand, and labeled/contrast agents (e.g. ${ }^{99 \mathrm{~m}} \mathrm{Tc},{ }^{177} \mathrm{Lu}$ ) to dendrimers have allowed the development of nontoxic, non-immunogenic, and tumor-specific $\mathrm{Au}(0)$ nanoparticles for 
KB HL60

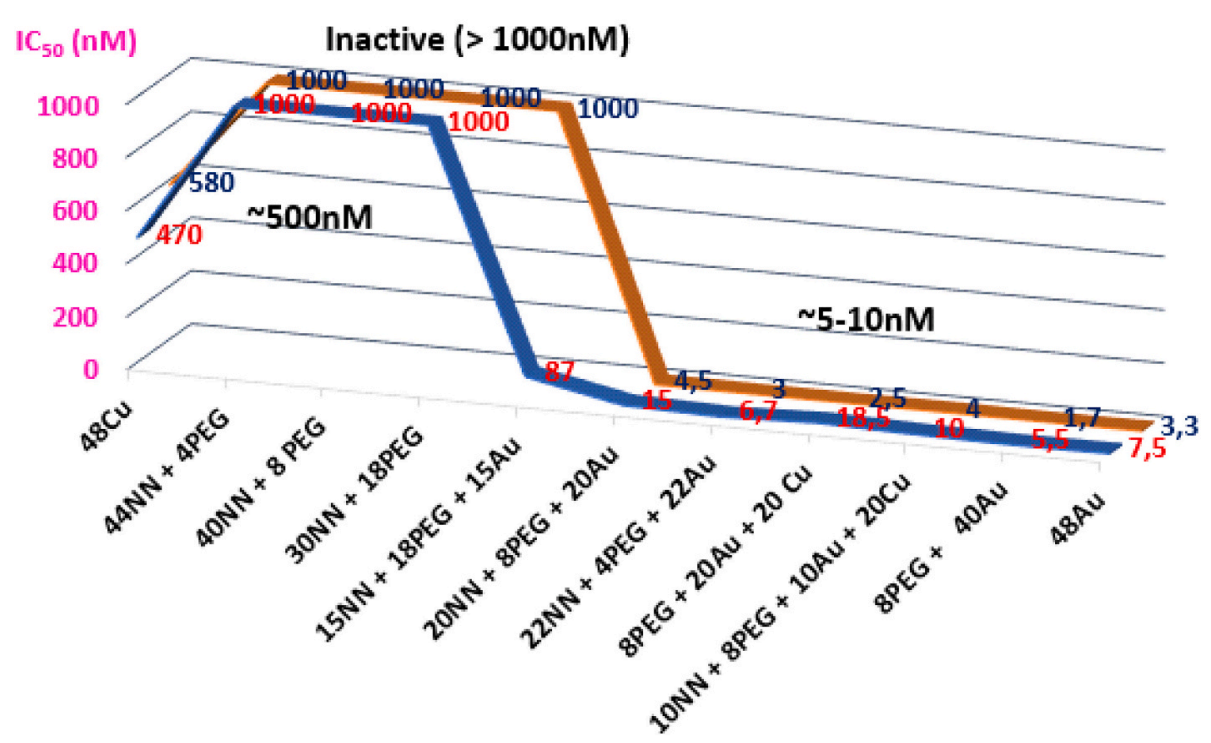

Fig. 9. Antiproliferative activies against KB and HL60 of prepared metaled and non-metaled phosphorous dendrimers.

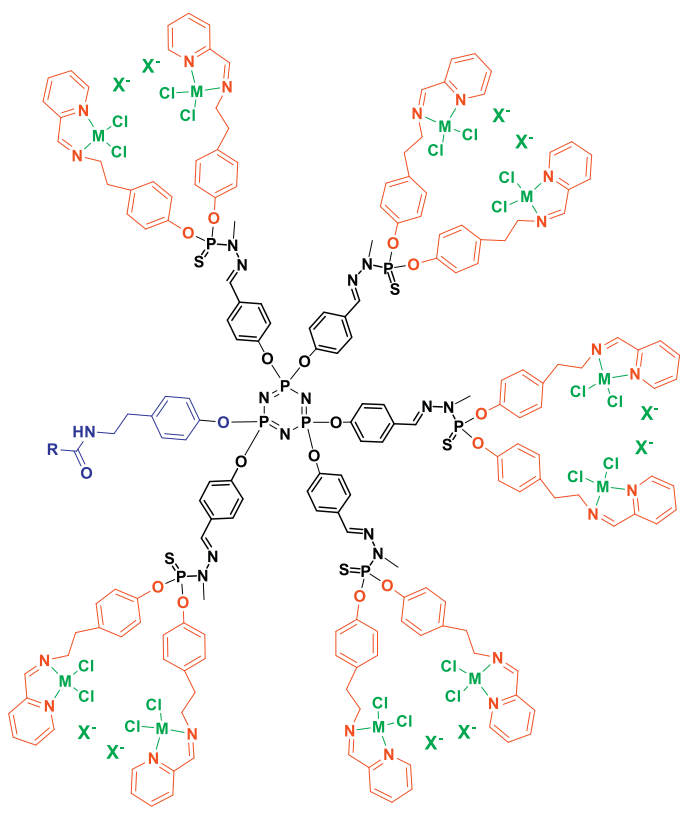

1GC11-Cu(II) : R = $\mathrm{C}_{11} \mathrm{H}_{23}, \mathrm{M}=\mathrm{Cu}(\mathrm{II})$ and $\mathrm{X}=$ none

1GC17-Cu(II): $\mathrm{R}=\mathrm{C}_{17} \mathrm{H}_{35}, \mathrm{M}=\mathrm{Cu}(\mathrm{II})$ and $\mathrm{X}=$ none

1GC11-Au(III): $R=\mathrm{C}_{11} \mathrm{H}_{23}, \mathrm{M}=[\mathrm{Au}]^{+}$and $\mathrm{X}=\mathrm{AuCl}_{4}$

1GC17-Au(III): $\mathrm{R}=\mathrm{C}_{17} \mathrm{H}_{35}, \mathrm{M}=[\mathrm{Au}]^{+}$and $\mathrm{X}=\mathrm{AuCl}_{4}$

Fig. 10. 2D chemical structure of 1GC11-Cu(II), 1GC17-Cu(II), 1GC11-Au(III) and 1GC17-Au(III).

dual mode SPECT/CT imaging of tumor cells in vitro and in vivo. SPECT and CT techniques are fully integrated and translated into clinical practice. This domain is innovative, for instance by the use of the ultrasound-targeted microbubble destruction (UTMD) technique to promote the simultaneous delivery of anticancer agents and genes. [109] The majority of studies used high generation of PAMAM dendrimers (e.g. G4-G5). Importantly, the development of low generation of PAMAM dendrimers (e.g. G2) has also been described to solve several pitfalls observed with high PAMAM generation, such as decreasing the cost of development and increasing the stability as well as the chemistry versatility for GMP grade production. [91]

Au DENPs are usually prepared using amine-terminated high-generation (G4 or above) PAMAM dendrimers as templates under appropriate $\mathrm{Au}$ salts/dendrimer molar ratio. [136] For biomedical applications, it is often required to modify the dendrimer terminal amines with acetyl groups. [137] However, in order to further improve the Au loading within the dendrimers and to improve the biocompatibility of Au DENPs without compromising their colloidal stability, the Au DENPs can always be prepared with dendrimers partially modified with PEG [138] or zwitterions, [139] followed by acetylation of the remaining dendrimer terminal amines. Table 4 presents a selection of chemical surface modifications of Au DENPs.

One of the hopes of the development of nanoparticles in oncology was to develop therapeutic nanoparticles with targeting agents to specifically target tumor cells. This has led to a plethora of publications but unfortunately, to date, no clinically approved drugs despite at least 30 years of research by many laboratories and pharmaceutical companies. The cost of the development of this type of dendrimer with targeting ligands remains an important issue. Consequently, the development of low generation of dendrimers could be an interesting approach, 


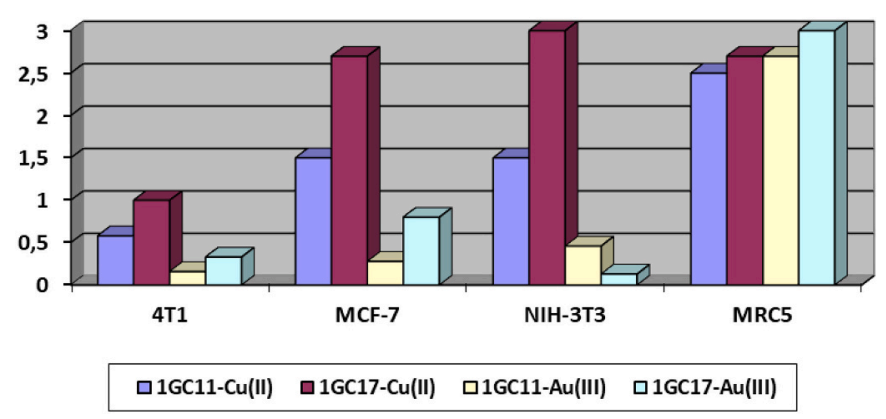

Fig. 11. Anti-proliferative activities (IC $\left.\mathrm{I}_{50} \mu \mathrm{M}\right)$ of 1GC11-Cu(II), 1GC17-Cu(II), 1GC11-Au(III)) and 1GC17-Au(III). IC 50 of 1GC-17-Cu(II) against NIH-3 T3 is $4.075 \pm 0.65 \mu \mathrm{M}$, and the $\mathrm{IC}_{50}$ of $\mathbf{1 G C - 1 7 - A u ( I I I )}$ against MRC5 is $3.18 \pm 0.27$ $\mu \mathrm{M}$ out of the vertical axis scale. The standard deviations are not presented, see ref. [133].

Table 4

Selection of chemical surface modifications of Au DENPs.

\begin{tabular}{|c|c|c|c|}
\hline Approach & $\begin{array}{l}\text { Dendrimer } \\
\text { types }\end{array}$ & Chemical surface moieties ${ }^{\mathrm{a}}$ & Ref. \\
\hline \multirow[t]{4}{*}{$\begin{array}{l}\text { Combined SPECT } \\
\text { and TC }\end{array}$} & G2 PAMAM & $\begin{array}{l}-\mathrm{NH}_{2} \text {, -Cyclic arginine-glycine- } \\
\text { aspartate motif (RDG) }{ }^{99 \mathrm{~m}} \mathrm{TC}\end{array}$ & [91] \\
\hline & G5 PAMAM & $\begin{array}{l}-\mathrm{NH}_{2} \text { or }-\mathrm{NHAc},-\mathrm{NHCH}_{2}-\mathrm{CH}(\mathrm{OH}) \\
\mathrm{CH}_{2} \mathrm{OH},-\mathrm{PEG},{ }^{99 \mathrm{~m}} \mathrm{TC}\end{array}$ & [84] \\
\hline & G2 PAMAM & -PEG, -Folic acid (FA), - $\mathrm{NH}_{2},{ }^{99 \mathrm{~m}} \mathrm{TC}$ & [94] \\
\hline & G5 PAMAM & $\begin{array}{l}\text {-PEG, - } \mathrm{NH}_{2}, \text {-Duramycin, }{ }^{99 \mathrm{~m}} \mathrm{TC} \\
\text { Fluoresceine isothiocynate (FI) }\end{array}$ & {$[87]$} \\
\hline \multirow[t]{5}{*}{$\mathrm{TC}$} & G5 PAMAM & $\begin{array}{l}\text {-NH } \mathrm{NH}_{2} \text {, -FI, -PEG-Tos (PEGylated } \\
\text { alpha-Tocophenyl succinate) }\end{array}$ & [99] \\
\hline & & -PEG-RDG, -NHAc, -PEG & [100] \\
\hline & & -NHAc, -PEG-OH, -PEG, Fluo-4 & [104] \\
\hline & & -FI, $-\mathrm{NH}_{2}$, lactobiomic acid & [105] \\
\hline & & -FI, -FA, -NHAc, diatrizoic acid & [99] \\
\hline \multirow[t]{2}{*}{ Ultrasound } & G5 PAMAM & -PEG, - $\mathrm{NH}_{2},-\mathrm{miR} 21$ & [102] \\
\hline & G4 PAMAM & $\begin{array}{l}\text {-FA, -Bombesin, -Gastrin-releasing } \\
\text { peptide receptor (GRPR) }\end{array}$ & [111] \\
\hline
\end{tabular}

\footnotetext{
${ }^{\text {a }}$ Ratio of the different moieties not indicated.
}

including the development of non-invasive functionalized Au DENPs in the theranostic field.

Another important point in the oncology domain is to improve the treatment of aggressive cancers encompassing triple negative breast cancers, glioblastoma, and pancreatic cancers, as developed by Shi et al. using ultrasound-targeted microbubble destruction (UTMD). [109] The treatment of metastatic cancers like breast cancers remains a challenge to be addressed by nanoparticle-based treatment. The development of first-in-class dendrimer/dendron-complexed gold(III) nanoparticles opens new avenues in the oncology domain, as highlighted by several original studies. [132,133]

Finally, in the nanomedicine domain, the translational pathway through the preclinical stage to clinical trials and the commercialization of dendrimers/dendrons included in the dendrimer space concept [8] as drugs or nanocarriers needs to be boosted in order to cross the "valley of death" between promising research and pharmaceutical industry resources for clinical trials. [140] A specific 2018 issue in honor of Prof. D. Tomalia advocated the recent advances in the field of properties and applications of dendrimers. [141] As so, aspects, like safety, polydispersity (or as recommended by IUPAC only dispersity) in different solvents, long term colloidal stability and lab scale-up, among, others cannot be forgotten in the development of the nanotherapeutics drugs in general and particularly in theranostic (radio)pharmaceuticals for cancer therapy.

\section{Declaration of Competing Interest}

The authors declare no conflict of interest.

\section{Acknowledgements}

X. Shi, S. Mignani and J-P. Majoral thank the PRC NSFC-CNRS 2019 (21911530230 for X.S. and 199675 for S.M. and J-P.M). J. Rodrigues, H. Tomas S. Mignani and X. Shi acknowledge the support of FCT-Fundação para a Ciência e a Tecnologia (Base Fund UIDB/00674/2020 and Programmatic Fund UIDP/00674/2020, Portuguese Government Funds) and ARDITI-Agência Regional para o Desenvolvimento da Investigação Tecnologia e Inovação through the project M1420-01-0145-FEDER$000005-\mathrm{CQM}^{+}$(Madeira 14-20 Program). S. Mignani, V. Ceña, and J-P. Majoral acknowledge transnational EuroNanoMed III funded projects including a proper acknowledgement of ERANET EuroNanoMed III and the respective funding partner organizations. V. Ceña acknowledges the support of the Spanish Ministerio de Economía y Competitividad (project SAF2017-89288-R from MINECO/AEI/FEDER/UE) and JCCM (project SBPLY/19/180501/000067). J. P. Majoral thanks CNRS (France) for financial support. Support from (COST European Cooperation in Science and Technology) through COST Action Nano2Clinic (CA17140) is also acknowledged.

\section{References}

[1] F. Farjadian, A. Ghasemi, O. Gohari, A. Roointan, M. Karimi, M.R. Hamblin, Nanomedicine 14 (2018) 93-126.

[2] S.D. Steichen, M. Caldorera-Moore, N.A. Peppas, Eur. J. Pharm. Sci. 48 (2013) $416-427$.

[3] D.A. Gewirtz, M.L. Molly, L. Bristol, J.C. Yalowich, Curr. Opin. Investig. Drugs 11 (2010) 612-614.

[4] D. Peer, J.M. Karp, S. Hong, O.C. Farokhzad, R. Margalit, R. Langer, Nat. Nanotechnol. 2 (2007) 751-760.

[5] T. Sun, Y.S. Zhang, B. Pang, D.C. Hyun, M. Yang, Y. Xia, Angew. Chem. Int. Ed. 53 (2014) 12320-12364.

[6] B. Fluhmann, I. Ntai, G. Borchard, S. Simoens, S. Muhlebach, Eur. J. Pharm. Sci. 128 (2019) 73-80.

[7] E. Abbasi, S.F. Fekri Aval, M. Akbarzadeh, H.T. Milani, S.W. Nasrabadi, Y. Joo, K. Nejati-Koshki Hanifehpour, R. Pashaei-Asl, Nanoscale Res. Lett. 9 (2014) 247.

[8] S. Mignani, S. El Kazzouli, M.M. Bousmina, J.-P. Majoral, Prog. Polym. Sci. 38 (2013) 993-1008.

[9] S. Mignani, S. El Kazzouli, M. Bousmina, J.-P. Majoral, Adv. Drug Deliv. Rev. 35 (2013) 1316-1330.

[10] B. Zhang, Y. Hu, Z. Pang, Front. Pharmacol. (2017) 952.

[11] U. Prabhakar, E.M. Sevick-Muraca, W. Zamboni, O.C. Farokhzad, S.T. Barry, A. Gabizon, P. Grodzinski, D.C. Blakey, Cancer Res. 73 (2013) 2412-2417.

[12] S. Mignani, X. Shi, J. Rodrigues, R. Roy, A. Muñoz-Fernández, V. Ceña, J. P. Majoral, Bioconjug. Chem. 31 (2020) 2060-2071.

[13] F. Danhier, J. Control. Release 244 (2016) 108-121.

[14] A.M. Alkilany, C.J. Murphy, J. Nanopart. Res. 12 (2010) 2313-2333.

[15] R. Shukla, V. Bansal, M. Chaudhary, A. Basu, R.R. Bhonde, M. Sastry, Langmuir 21 (2005) 10644-10654

[16] B. Li, L.A. Lane, Wiley Interdiscip. Rev. Nanomed. Nanobiotechnol. 11 (2019), e1542.

[17] E.C. Dreaden, M.A.M. Alkilany, X. Huang, C.J. Murphy, A.A. El-Sayed, Chem. Soc. Rev. 41 (2012) 2740.

[18] X. Li, K. Kono, Polym. Int. 67 (2018) 840-852.

[19] S. Hapuarachchige, D. Artemov, Front. Oncol. 10 (2020) 1131.

[20] G. Lymperopoulos, P. Lymperopoulos, V. Alikari, C. Dafogianni, S. Zyga, N. Margari, Adv. Exp. Med. Biol. 989 (2017) 119-128.

[21] C. Zavaleta, D. Ho, E.J. Chung, SLAS Technol. 23 (2018) 281-293.

[22] A. Jurj, C. Braicu, L.-A. Pop, C. Tomuleasa, C.D. Gherman, I. Berindan-Neagoe, Drug Des. Develop. Ther. 11 (2017) 2871-2890.

[23] F. Chen, E.B. Ehlerding, W. Cai, J. Nucl. Med. 55 (2014) 1919-1922.

[24] C. Li, Y. Zhang, Z. Li, E. Mei, J. Lin, F. Li, C. Chen, X. Qing, L. Hou, L. Xiong, H. Hao, Y. Yang, P. Huang, Adv. Mater. 30 (2017) 1706150.

[25] J.L. Paris, M.V. Cabañas, M. Manzano, M. Vallet-Regí, ACS Nano 9 (2015) $11023-11033$.

[26] N. Lu, P. Huang, W. Fan, Z. Wang, Y. Liu, S. Wang, G. Zhang, J. Hu, W. Liu, G. Niu, R.D. Leapman, G. Lu, X. Chen, Biomaterials 126 (2017) 39-48.

[27] Z. Yang, W. Fan, J. Zou, W. Tang, L. Li, L. He, Z. Shen, Z. Wang, O. Jacobson, M. A. Aronova, P. Rong, J. Song, W. Wang, X. Chen, J. Am. Chem. Soc. 141 (2019) $14687-14698$.

[28] J. Gautier, E. Allard-Vannier, E. Munnier, M. Soucé, I. Chourpa, J. Control. Release 169 (2013) 48-61.

[29] R.C.R. dos Apostolos, M.F. Cipreste, R.G. de Sousa, E.M.B. de Sousa, J. Nanopart. Res. 22 (2020) 368. 
[30] Z. Yang, W. Fan, J. Zou, W. Tang, L. Li, L. He, Z. Shen, Z. Wang, O. Jacobson, M. A. Aronova, P. Rong, J. Song, W. Wang, X. Chen, J. Am. Chem. Soc. 141 (2019).

[31] S. Mignani, J. Rodrigues, H. Tomas, A.-M. Caminade, R. Laurent, X. Shi, J.P. Majoral, Sci. China Mater. 61 (2018) 1367-1386.

[32] S. Dhar, Z. Liu, J. Thomale, H. Dai, S.J. Lippard, J. Am. Chem. Soc. 130 (2008) $11467-11476$

[33] D.B. Pike, H. Ghandehari, Adv. Drug Deliv. Rev. 62 (2010) 167-183.

[34] X. Gao, Y. Luo, Y. Wang, J. Pang, C. Liao, H. Lu, Y. Fang, IJN 7 (2012) 4037-4051.

[35] M. Talelli, C.J.F. Rijcken, C.F. van Nostrum, G. Storm, W.E. Hennink, Adv. Drug Deliv. Rev. 62 (2010) 231-239.

[36] V.I. Shubayev, T.R. Pisanic, S. Jin, Adv. Drug Deliv. Rev. 21 (2009) 467-477.

[37] J. Tan, N. Yang, L. Zhong, J. Tan, Z. Hu, Q. Zhao, W. Gong, Z. Zhang, R. Zheng, Z. Lai, Y. Li, C. Zhou, G. Zhang, D. Zheng, Y. Zhang, S. Wu, X. Jiang, J. Zhong, Y. Huang, S. Zhou, Y. Zhao, Theranostics 7 (2017) 4862-4876.

[38] L. Chen, X. Zhou, W. Nie, Q. Zhang, W. Wang, Y. Zhang, C. He, ACS Appl. Mater. Interfaces 8 (2016) 33829-33841.

[39] D. Wang, H. Lin, G. Zhang, Y. Si, H. Yang, G. Bai, C. Yang, K. Zhong, D. Cai, Z. Wu, R. Wang, D. Zou, ACS Appl. Mater. Interfaces 10 (2018) 31114-31123.

[40] D. Wang, H. Lin, G. Zhang, Y. Si, H. Yang, G. Bai, C. Yang, K. Zhong, D. Cai, Z. Wu, R. Wang, D. Zou, ACS Appl. Mater. Interfaces 10 (2018) 31114-31123.

[41] W.-H. Chen, G.-F. Luo, W.-X. Qiu, Q. Lei, L.-H. Liu, S.-B. Wang, X.-Z. Zhang, Biomaterials 117 (2017) 54-65.

[42] E. Guisasola, L. Asín, L. Beola, J.M. de la Fuente, A. Baeza, M. Vallet-Regí, ACS Appl. Mater. Interfaces 10 (2018) 12518-12525.

[43] Z. Wang, Z. Chang, M. Lu, D. Shao, J. Yue, D. Yang, X. Zheng, M. Li, K. He, M. Zhang, L. Chen, W.-F. Dong, Biomaterials 154 (2018) 147-157.

[44] A.A. Barbosa, S.A. Alves Júniora, R.L. Luciane Mendes, R.S. de Lima, A. de Vasconcelos Ferraz, Mater. Sci. Eng. C Mater. Biol. Appl. 116 (2020) 111227

[45] C. Dong, W. Feng, W. Xu, L. Yu, H. Xiang, Y. Chen, J. Zhou, Adv. Mater. 28 (2016) 8927-8936.

[46] S. Zhang, C. Sun, J. Zeng, Q. Sun, G. Wang, Y. Wang, Y. Wu, S. Dou, M. Gao, Z. Li, Adv. Mater. 28 (2016) 8927-8936.

[47] J. Shen, H.-C. Kim, J. Wolfram, C. Mu, W. Zhang, H. Liu, Y. Xie, J. Mai, H. Zhang, Z. Li, M. Guevara, Z.-W. Mao, H. Shen, Nano Lett. 17 (2017) 2913-2920.

[48] X.-C. Zheng, W. Ren, S. Zhang, T. Zhong, X.-C. Duan, Y.-F. Yin, M.-Q. Xu, Y.L. Hao, Z.-T. Li, H. Li, M. Liu, Z.-Y. Li, X. Zhang, Int. J. Nanomedicine 13 (2018) 1495-1504.

[49] X. Cheng, R. Sun, L. Yin, Z. Chai, H. Shi, M. Gao, Adv. Mater. 29 (2016) 1604894.

[50] M. Theodosiou, N. Boukos, E. Sakellis, M. Zachariadis, E.K. Efthimiadou, Colloids Surf. B: Biointerfaces 183 (2019) 110420.

[51] B. Giorain, H. Choudhury, A.B. Nair, S.K. Dubey, P. Kesharwani, Drug Discov. Today 25 (2020) 1174-1188.

[52] T.P. Thomas, R. Shukla, K. Alina, J. Kukowska-Latallo, J.R. Baker, Bioorg. Med. Chem. Lett. 20 (2010) 700-703.

[53] S.K. Choi, T. Thomas, M.H. Li, A. Kotlyar, A. Desai, J.R. Baker, Chem. Commun 46 (2010) 2632-2634.

[54] Y. Zhao, S. Liu, Y. Li, W. Jiang, Y. Chang, S. Pan, X. Fang, Y.A. Wang, J. Wang, J. Colloid Interface Sci. 350 (2010) 44-50.

[55] Y. Li, X. Zhang, X. Xu, Z. Zhang, C. Hu, Y. He, Z. Gu, Theranostics 6 (2016) 1293-1305.

[56] S. Aime, P. Caravan, J. Magn. Reson. Imaging 30 (2009) 1259-1267.

[57] E. Wiener, M.W. Brechbiel, H. Brothers, E.C. Wiener, M.W. Brechbiel, H. Brothers R.L. Magin, O.A. Gansow, D.A. Tomalia, P.C. Lauterbur, Magn. Reson. Med. 31 (1994) 1-8.

[58] S.D. Konda, M.A. Aref, S. Wang, M. Brechbiel, E.C. Wiener, Magna 12 (2001) 104-113.

[59] R. Xu, Y. Wang, X. Wang, E.-K. Jeong, D.L. Parker, Z.-R. Lu, Exp. Biol. Med. (Maywood) 232 (2007) 1081-1089.

[60] M. Filippi, V. Catanzaro, D. Patrucco, M. Botta, L. Tei, E. Terreno, J. Control. Release 248 (2017) 45-52.

[61] J.M. Criscione, B.L. Le, E. Stern, M. Brennan, C. Rahner, X. Papademetris, T, M. Fahmy, Biomaterials 30 (2009) 3946-3955.

[62] D. Luong, S. Sau, P. Kesharwani, K. Arun, Biomacromolecules 18 (2017) 1197-1209.

[63] T.W. Mekonnen, Y.S. Birhan, A.T. Andrgie, E.Y. Hanurry, H.F. Darge, H.-Y. Chou, J.-Y. Lai, H.-C. Tsai, J.M. Yang, Y.-H. Chang, Colloids Surf. B: Biointerfaces 184 (2019) 110531.

[64] A. Almutairi, R. Rossin, M. Shokeen, A. Hagooly, A. Ananth, B. Capoccia, S. Guillaudeu, D. Abendschein, C.J. Anderson, M.J. Welch, J.M.J. Fréchet, Proc. Natl. Acad. Sci. U. S. A. 106 (2009) 685-690.

[65] N. Li, Y. Jin, L.Z. Xue, P.-Y. Li, Chin. J. Polym. Sci. 3 (2013) 530-540.

[66] J. Zhu, L. Zhao, Y. Cheng, Z. Xiong, Y. Tang, M. Shen, J. Zhao, X. Shi, Nanoscale 7 (2015) 18169-18178.

[67] L. Zhao, J. Zhu, Y. Cheng, Z. Xiong, Y. Tang, L. Guo, X. Shi, J. Zhao, ACS Appl. Mater. Interfaces 7 (2015) 19798-19808.

[68] M.V. Backer, T.I. Gaynutdinov, V. Patel, A.K. Bandyopadhyaya, B.T. S. Thirumamagal, W. Tjarks, R.F. Barth, K. Claffey, J.M. Backer, Mol. Cancer Ther. 4 (2005) 1423-1429.

[69] R. Ge, J. Cao, J. Chi, S. Han, Y. Liang, L. Xu, M. Liang, Y. Sun, Int. J. Nanomedicine 14 (2019) 4931-4947.

[70] D. Tyssen, S.A. Henderson, A. Johnson, J. Sterjovski, K. Moore, J. La, M. Zanin, S. Sonza, P. Karellas, M.P. Giannis, G. Krippner, S. Wesselingh, T. McCarthy, P. R. Gorry, P.A. Ramsland, R. Cone, J.R.A. Paull, G.R. Lewis, G. Tachedjian, PLoS One 5 (2010), e12309.

[71] StarPharma, 2021 [Accessed January 2021].
[72] Alnylam, 2021 [Accessed January 2021].

[73] C. Zhou, S. Yang, J. Liu, M. Yu, J. Zheng, Exp. Biol. Med. (Maywood) 238 (2013) 1199-1209.

[74] S.D. Jo, S.H. Ku, Y.Y. Won, S.H. Kim, I.C. Kwon, Theranostics (2016) 1362-1377.

[75] H. Daraee, A. Eatemadi, E. Abbasi, S.F. Aval, M. Kouhi, A. Akbarzadeh, Artif. $]$ Cells, Nanomed. B. (2016) 410-422.

[76] T. Cao, X. Zhou, Y. Zheng, Y. Sun, J. Zhang, W. Chen, J. Zhang, Z. Zhou, S. Yang, Y. Zhang, H. Yang, M. Wang, ACS Appl. Mater. Interfaces 9 (2017) 42612-42621.

[77] N. Lee, S.H. Choi, T. Hyeon, Adv. Mater. 25 (2013) 2641-2660.

[78] C.-H. Yeong, M.-H. Cheng, K.-H. Ng, J Zhejiang Univ Sci B 15 (2014) 845-863.

[79] Y. Wang, Y. Wu, Y. Liu, J. Shen, L. Lv, L. Li, L. Yang, J.J. Zeng, Y. Wang, L. Zhang, Z. Li, M. Gao, Z. Chai, Adv. Funct. Mater. 26 (2016) 5335-5344.

[80] S. Mignani, J. Rodrigues, H. Tomas, A.M. Caminade, R.R. Laurent, X. Shi, J. P. Majoral, Sci. China Mater. 61 (2018) 1367-1386.

[81] T. Xiao, D. Li, X. Shi, M. Shen, Macromol. Biosci. 20 (2020), e1900282.

[82] J.-P. Majoral, M. Zablocka, A.M. Caminade, P. Balczewski, X. Shi, S. Mignani, Coord. Chem. Rev. 358 (2018) 80-91.

[83] M.B. Camarada, Chem. Phys. Lett. 654 (2016) 29-36.

[84] A.E. Enciso, G. Doni, R. Nifosì, F. Palazzesi, R. Gonzalez, A.A. Ellsworth, J. L. Coffer, A.V. Walker, G.M. Pavan, A.A. Mohameda, E.E. Simanek, Nanoscale 9 (2017) 3128-3132.

[85] H. Wang, L.F. Zheng, C. Peng, R. Guo, M. Shen, X. Shi, C. Zhang, Biomaterials 32 (2011) 2979-2988.

[86] M. Shen, X. Shi, Nanoscale 2 (2010) 1027-1032.

[87] C. Peng, J. Qin, B. Zhou, Q. Chen, M. Shen, M. Zhu, X. Lu, X. Shi, Polym. Chem. 4 (2013) 4412-4424.

[88] D. Hu, Y. Huang, H. Liu, H. Wang, S. Wang, M. Shen, M. Zhu, X. Shi, J. Mater. Chem. A 2 (2014) 2323-2332.

[89] M.B. Camarada, J. Comer, H. Poblete, E.R.A. Singam, V. Marquez-Miranda, C. Morales-Verdejo, F.D. Gonzalez-Nilo, Langmuir 34 (2018) 10063-100072.

[90] T. Zhou, Y. Wang, Y. Dong, C. Chen, D. Liu, Z. Yang, Bioorg. Med. Chem. 22 (2014) 4391-4394.

[91] X. Xu, L. Zhao, X. Li, P. Wang, J. Zhao, X. Shi, M. Shen, Biomater. Sci. (2017) 2393-2397.

[92] S. Wen, L. Zhao, Q. Zhao, D. Li, C. Liu, Z. Yu, M. Shen, J.-P. Majoral, S. Mignani, J. Zhao, X. Shi, J. Mater. Chem. B (2017) 3810-3815.

[93] F. Shi, C. Peng, Y. Yanga, Y. Sha, X. Shi, H. Wu, Colloid Surf. A 497 (2016) 194-204.

[94] X. Li, Z. Xiong, X. Xu, Y. Luo, C. Peng, M. Shen, X. Shi, ACS Appl. Mater. Interfaces 8 (2016) 19883-19891.

[95] Y. Xing, J. Zhu, L. Zhao, Z. Xiong, Y. Li, S. Wu, G. Chand, X. Shi, J. Zhao, Drug Deliv. 25 (2018) 1384-1393.

[96] M.G. Roncarolo, M. Battaglia, Nat. Rev. Immunol. 7 (2007) 585-598.

[97] A. Li, J. Qiu, B. Zhou, B. Xu, Z. Xiong, X. Hao, X. Shi, X. Cao, Arab. J. Chem. 13 (2020) 2558-2567.

[98] J. Zhu, F. Fu, Z. Xiong, M. Shen, X. Shi, Collod. Surface B, Biointerfaces 133 (2015) 36-42.

[99] A. Angulo-Molina, J. Reyes-Leyva, A. López-Malo, J. Hernández, J. Nutr. Cancer (2014) 167-176.

[100] R. Guo, H. Wang, C. Peng, M. Shen, L. Zheng, G. Zhang, X. Shi, J. Mater. Chem. A 21 (2011) 5120-5127.

[101] K. Li, Z. Zhang, L. Zheng, H. Liu, W. Wei, Z. Li, Z. He, A.C. Larson, G. Zhang, Nanomedicine (London) 10 (2015) 2185-2197.

[102] H. Liu, H. Wang, Y. Xu, M. Shen, J. Zhao, G. Zhang, X. Shi, Nanoscale 6 (2014) $4521-4526$.

[103] Y. Li, L. Zhao, X. Xu, N. Sun, W. Qiao, Y. Xing, M. Shen, M. Zhu, X. Shi, J. Zhao, J. Biomed. Nanotechnol. 15 (2019) 1201-1212.

[104] M. Chen, O. Betzer, Y. Fan, Y. Gao, M. Shen, T. Sadan, R. Popovtzer, X. Shi, Biomacromolecules 21 (2020) 1587-1595.

[105] H. Liu, H. Wang, Y. Xu, R. Guo, S. Wen, Y. Huang, W. Liu, M. Shen, J. Zhao, X. Shi Zhang, ACS Appl. Mater. Interfaces 6 (2014) 6944-6953.

[106] J. Lin, W. Hu, F. Gao, J. Qin, C. Peng, X. Lu, J. Cancer 9 (2018) 564-577.

[107] C. Peng, K. Li, X. Cao, T. Xiao, W. Hou, L. Zheng, R. Guo, M. Shen, G. Zhang, X. Shi, Nanoscale 7 (2012) 6768-6778.

[108] F. Shi, Y. Yang, J. Chen, Y. Sha, Y. Shu, H. Wu, Hindawi BioMed Res Int (2018), 1230151, https://doi.org/10.1155/2018/1230151.

[109] L. Lin, Y. Fan, F. Gao, L. Jin, D. Li, W. Sun, F. Li, P. Qin, Q. Shi, X. Shi, D. Du, Theranostics 8 (2018) 1923-1939.

[110] H. Mendoza-Nava, G. Ferro-Flores, F. de Maria Ramirez, B. Ocampo-Garcia, C. Santos-Cuevas, L. Aranda-Lara, E. Azorin-Vega, E. Morales-Avila, K. IsaacOlive, J. Nanomater. (2016), 1039258, https://doi.org/10.1155/2016/1039258.

[111] H. Mendoza-Nava, G. Ferro-Flores, F. de Maria Ramirez, B. Ocampo-Garcia, C. Santos-Cuevas, E. Azorin-Vega, N. Jimenez-Mancilla, M. Luna-Gutierrez, K. Isaac-Olive, Mol. Imaging (2017) 16, 1536012117704768.

[112] L. Zhao, M. Zhu, Y. Li, Y. Xing, J. Zhao, Molecules 22 (2017) 1350.

[113] M.K. Khan, L.D. Minc, S.S. Nigavekar, M.S.T. Kariapper, B.M. Nair, M. Schipper, A.C. Cook, W.G. Lesniak, L.P. Balogh, Nanomedicine 4 (2008) 57-69.

[114] S. Janitabar-Darzi, R. Rezaei, K. Yavari, Adv. Pharm. Bull. 7 (2017) 87-95.

[115] Y. Yue, C. Wu, Biomater. Sci. 1 (2013) 152-170.

[116] J. Qiu, L. Kong, X. Cao, A. Li, P. Wei, L. Wang, S. Mignani, A.M. Caminade, J.P. Majoral, X. Shi, Nanomaterials 8 (2018) 131.

[117] W. Hou, P. Wei, L. Kong, R. Guo, S. Wang, X. Shi, J. Mater. Chem. B 4 (2016) 2933-2943.

[118] Z. Bengali, A.K. Pannier, T. Segura, B.C. Anderson, J.-H. Jang, T.A. Mustoe, L. D. Shea, Biotechnol. Bioeng. 90 (2005) 290-302. 
[119] Z. Xiong, C.S. Alves, J. Wang, A. Li, J. Liu, M. Shen, J. Rodrigues, H. Tomás, X. Shi, Acta Biomater. 99 (2019) 320-329.

[120] L.S. Mbatha, M. Singh, J. Nanosci. Nanotechnol. 19 (2019) 1959-1970.

[121] L.S. Mbatha, F.C. Maiyo, M. Singh, Acta Pharma. 69 (2019) 49-61.

[122] J. Zhu, G. Wang, C.S. Alves, H. Tomás, Z. Xiong, M. Shen, J. Rodrigues, X. Shi, Langmuir 34 (2018) 12428-12435.

[123] M. Alibolandi, F. Hoseini, M. Mohammadi, P. Ramezani, E. Einafshar, Int. J. Pharm. 549 (2018) 67-75.

[124] Z. Xu, N. Joshi, A. Agarwal, S. Dahiya, P. Bittner, E. Smith, S. Taylor, D. PiwnicaWorms, J. Weber, J.R. Leonard, J. Neuro-Oncol. 108 (2012) 59-67.

[125] X. Wang, X. Cai, J. Hu, N. Shao, F. Wang, Q. Zhang, J. Xiao, Y. Cheng, J. Am. Chem. Soc. 135 (2013) 9805-9810.

[126] Y. Haba, C. Kojima, A. Harada, T. Ura, H. Horinaka, K. Kono, Langmuir 23 (2007) 5243-5246.

[127] P. Dong, J.Y. Xin, X. Yang, J. Jia, W. Wu, J.S. JLi, RSC Adv. 4 (2014) $44872-44878$.

[128] X.Y. Wang, H.L. Wang, Y.T. Wang, X.T. Yu, S.J. Zhang, Q. Zhang, Y.Y. Cheng, Sci. Rep. 6 (2016) 22764.

[129] S. El Kazzouli, N. El Brahmi, S. Mignani, M.M. Bousmina, M. Zablocka, J.P. Majoral, Curr. Med. Chem. 19 (2012) 4995-5010.

[130] S. Mignani, N. El Brahmi, L. Eloy, J. Poupon, V. Nicolas, A. Steinmetz, S. E] Kazzouli, M.M. Bousmina, M. Blanchard-Desce, A.-M. Caminade, J.-P. Majoral, T. Cresteil, Eur. J. Med. Chem. 132 (2017) 142-156.
[131] S. Mignani, N. El Brahmi, T. Cresteil, J.-P. Majoral, Phosphorus dedrimers in biology and nanomedicine, Ed. A-M Caminade, C-O. Turrin, J-P. Majoral Chapter 9 (2018) Pan Stanford Publishing.

[132] S. Mignani, N. El Brahmi, S. El Kazzouli, R. Laurent, S. Sonia Ladeira, A.M. Caminade, E. Pedziwiatr-Werbicka, E.M. Szewczyk, M. Bryszewska, M. M. Bousmina, T. Cresteil, J.-P. Majoral, Mol. Pharm. 14 (2017) 4087-4097.

[133] L. Chen, Y. Fan, J. Qiu, R. Laurent, J. Bignon, S. Mignani, A.M. Caminade, X. Shi, J.-P. Majoral, Chem. Eur. J. 26 (2020), https://doi.org/10.1002/ chem.202001014.

[134] J. Wolfram, M. Ferrari, Nanotoday 25 (2019) 85-98.

[135] S. Wilhelm, A.J. Tavares, Q. Dai, S. Ohta, J. Audet, H.F. Dvorak, W.C.W. Chan, Nat. Rev. Mater. 1 (2016), 16014.

[136] R. Guo, H. Wang, C. Peng, M. Shen, M. Pan, X. Cao, G. Zhang, X. Shi, J. Phys. Chem. C 114 (2010) 50-56.

[137] C. Peng, H. Wang, R. Guo, M. Shen, X. Cao, M. Zhu, G. Zhang, X. Shi, J. Appl. Polym. Sci. 119 (2011) 1673-1682.

[138] C. Peng, L. Zheng, Q. Chen, M. Shen, R. Guo, H. Wang, X. Cao, G. Zhang, X. Shi, Biomaterials 33 (2012) 1107-1119.

[139] J. Liu, Z. Xiong, J. Zhang, C. Peng, B. Klajnert-Maculewicz, M. Shen, X. Shi, ACS Appl. Mater. Interfaces 11 (2019) 15212-15221.

[140] S. Mignani, X. Shi, J. Rodrigues, R. Roy, A. Muñoz-Fernández, V. Ceña, J.P. Majoral, Bioconjug. Chem. 31 (9) (2020) 2060-2071.

[141] A. Kakkar (Ed.), Molecules, Mc Gill University, 2018, p. 3. 